Portland State University

PDXScholar

1978

\title{
Toward a model of interorganizational fields : a case study of a social service federation
}

Ralph Cherry

Portland State University

Follow this and additional works at: https://pdxscholar.library.pdx.edu/open_access_etds

Part of the Work, Economy and Organizations Commons Let us know how access to this document benefits you.

\section{Recommended Citation}

Cherry, Ralph, "Toward a model of interorganizational fields : a case study of a social service federation" (1978). Dissertations and Theses. Paper 2861.

https://doi.org/10.15760/etd.2857

This Thesis is brought to you for free and open access. It has been accepted for inclusion in Dissertations and Theses by an authorized administrator of PDXScholar. Please contact us if we can make this document more accessible: pdxscholar@pdx.edu. 
AN ABSTRACT OF THE THESIS OF Ralph Cherry for the Master of Science in Sociology presented April 15, 1978.

Title: Toward a Model of Interorganizational Fields: A Case Study of a Social Service Federation

APPROVED BY MEMBERS OF THE THESIS COMMITTEE:

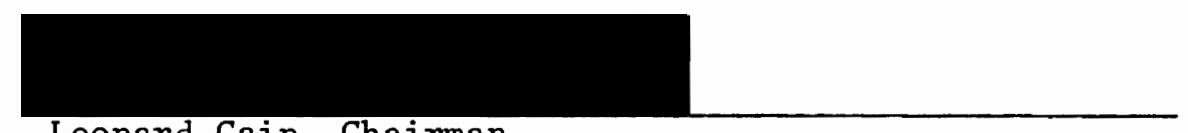

Leonard Cain, Chairman

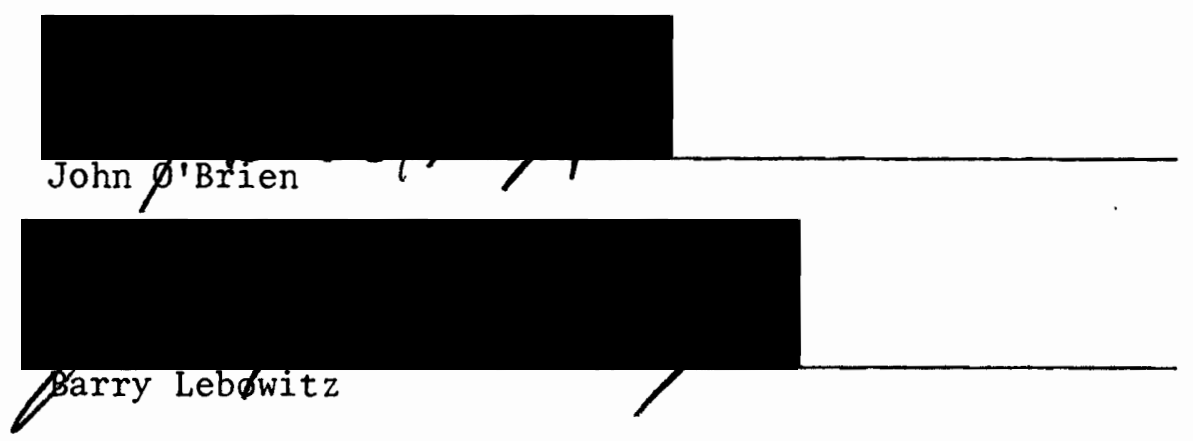

The concept of interorganizational field refers to the pattern of relationships or the context within which organizations negotiate or compete to accomplish their goals. This paper examines the proposition that the type of interorganizational field shapes and influences interactions between organizations. To explore the nature of any contextual effects, a hypothesis is extracted to represent each of four subareas of the literature: the transaction or exchange, the resource dependency, the communication, and the division of labor subareas. Nonverification of the hypotheses indicates the extent and the manner in which interorganizational fields can affect relations between organiza- 
tions.

A case study of these hypotheses is presented for one type of interorganizational field, a federation of social service agencies. The federation includes eight organizations which delivered services • and an administrative component to facilitate interagency coordination. The data, which were gathered from project documents, monthly records, and a series of interviews of representatives from each of these organizations, permit analysis of the federation's two-year tenure. Analysis of these data leave three of the four hypotheses not verified, with only the hypothesis on communication between organizations being upheld. These findings suggest that the "norms of rationality" alleged to govern organizational decision-making are actually assessed according to characteristics of the interorganizational context. More generally, the conclusion is that the interorganizational field level of analysis merits further examination as a causal context. By specifying the nature of this context, it ultimately is possible to theorize whether the effects of variables across fields are linear or curvilinear, and whether interaction effects exist. 
TOWARD A MODEL OF INTERORGANIZATIONAL FIELDS:

A CASE STUDY OF A SOCIAL SERVICE FEDERATION

by

Ralph Cherry

A thesis submitted in partial fulfillment of the requirements for the degree of

\author{
MASTERS OF SCIENCE \\ in \\ SOCIOLOGY
}

Portland State University

1978 
TO THE OFFICE OF GRADUATE STUDIES AND RESEARCH:

The members of the Committee approve the thesis of Ralph Cherry presented April 15,1978.

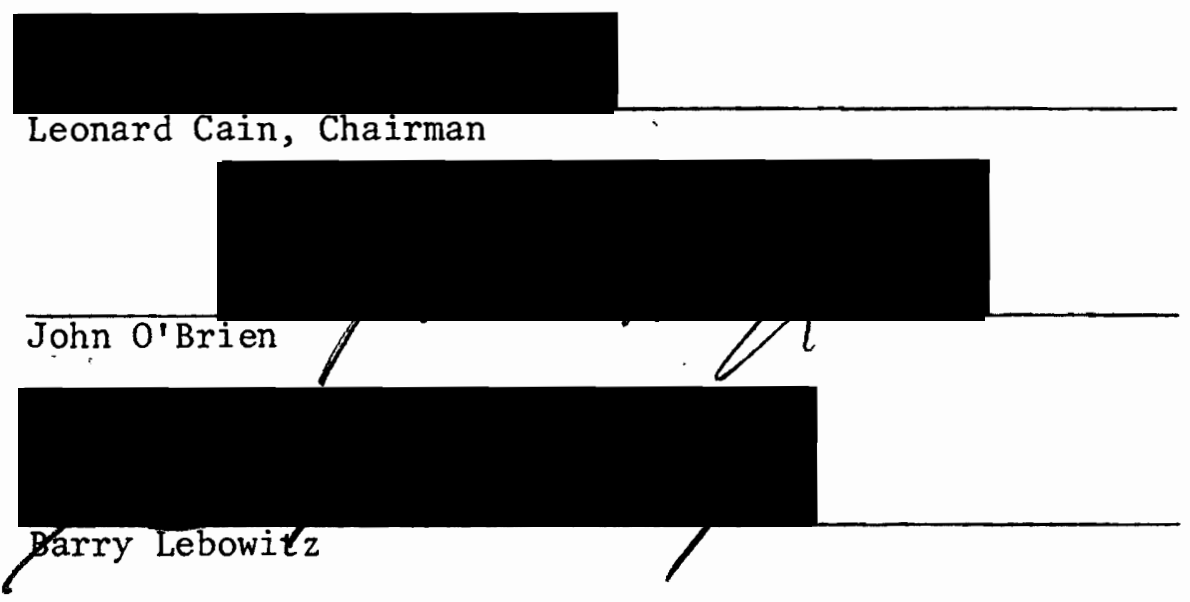

APPROVED :
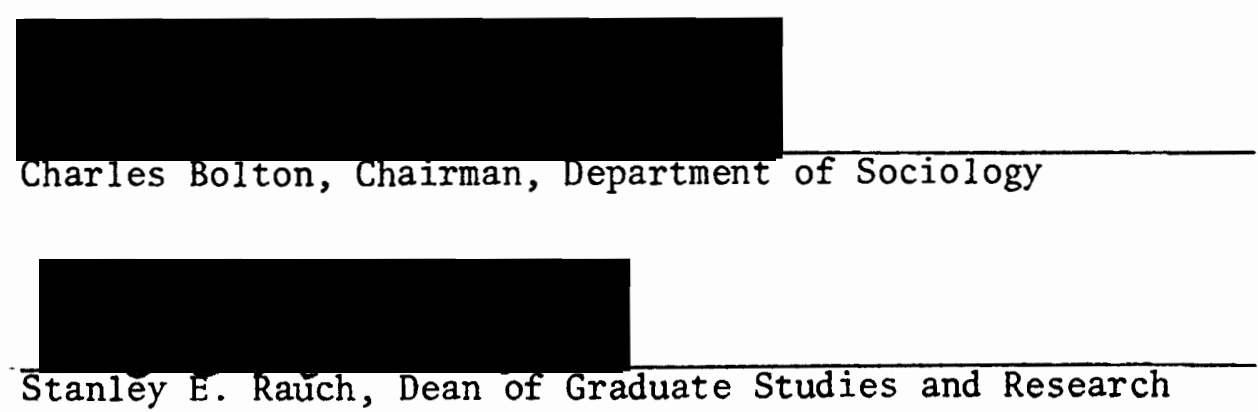


\section{ACKNOWLEDGMENTS}

This thesis was written while receiving a predoctoral fellowship from the Midwest Council for Social Research on Aging. The data for the thesis was gathered under grants to the Institute on Aging (of Portland State University) from the Oregon State Program on Aging, the city of Portland, and Multnomah County to evaluate an interagency model service project for older people. Appreciation is expressed to the many representatives of those agencies who cooperated with the interviewing process and to the Institute for the use of the data. I thank the many people at the Institute who were both encouraging and interested in discussing issues in coordinating services and in interorganizational relations; this includes John O'Brien, Leonard Cain, Jan Hajda, Barry Lebowitz (now at National Institute of Mental Health), Nancy Whitelaw, Mike DeShane, and Tim Stearns (now at Indiana University). Also, at the University of Minnesota, I appreciated the many Friday afternoon discussions with sociology graduate students; my chats with Leslie Brown were especially helpful. Finally, my deepest appreciation is extended to Karen Adair, who for the last two years has been my favorite source of encouragement and stimulating discussion. 
TABLE OF CONTENTS

PAGE

ACKNOWLEDGMENTS ..................

LIST OF TABLES . . . . . . . . . . . . . . vi

LIST OF FIGURES ................... . . vii

CHAPTER

I CONCEPT OF INTERORGANIZATIONAL FIELDS...... .1

Introduction

Towards an Interorganizational Perspective . . 5

A Typology of Interorganizational Fields Prospects . . . . . . . . . . 9

The Interorganizational Field - Problems . . 14

II APPROACHES TO INTERORGANIZATIONAL RELATIONSHIPS . . 17

Organizational Centered Approach . . . . 18

Relational Approach . . . . . . . . 27

Examining Interorganizational Fields: A

Typology and Hypotheses ... . . . . . 35

Contextual Effects of Federations: Alternative Conceptualizations . . . . . 38

III FEDERATION OF SERVICE AGENCIES ........ 41

Multiorganizational Service Project . . . . . 41

IV METHODOLOGY ............. 48

Case Study Method: Limitations and Possibilities . . . . . . . . 48

Data Collection . . . . . . . . 49 
Data Analysis . . . . . . . . . . 53

V AN EMPIRICAL EXAMINATION OF HYPOTHESES. . . . . . 57

Transactional Subarea . . . . . . . . 57

Managerial Subarea . . . . . . . . 65

Communication Subarea . . . . . . . . 74

Division of Labor Subarea . . . . . . . 83

Impact of the Federation of Interorganizational

Relationships . . . . . . . . . . 91

VI CONCLUSION: TOWARD A MODEL OF INTERORGANIZATIONAL

FIELDS • • • • • • • • • • • • • • • 98

REFERENCES . . . . . . . . . . . . . . . . . . 105 


\section{LIST OF TABLES}

TABLE

PAGE

I Number of Clients (Aggregated in 4-Month Spans) Referred to Service Agencies By Referral Agencies . . . . . 70

II Referral Rejections for Three Project Agencies During

Eight Months of First Year . . . . . . . . . . 80 


\section{LIST OF FIGURES}

\section{FIGURE}

PAGE

1 Four Subareas of Interorganization Relations . . . . 36 


\section{CHAPTER I}

\section{THE CONCEPT OF INTERORGANIZATIONAL FIELDS}

\section{Introduction}

In a sense, many of the issues predominant in contemporary American society can be subsumed under an analysis of relationships between organizations. Broadly described, this topic encompasses a gamut of organizational forms, ranging in size and power from large business conglomerates to the local grocery store and in complexity from the federal bureaucracy to neighborhood voluntary associations. The settings for interaction between such organizations can range from the diplomacy of international contexts and race relations, to the provision of community services, to profit-making enterprise. And finally, interorganizational relationships also subsume a diversity of interactional styles, including conflict, competition, cooperation, clandestine associations, and overt contracts or treaties.

One particular societal focus of late which has provided an impetus for interorganizational research involves the innovations in the relationships among human service agencies. In recent years, for example, the design for social welfare has shifted somewhat from strategies emphasizing the funding of services and income subsidies to a strategy of funding the organization of community services (Rothman, 1974). This orientation culminated in a number of federally sponsored programs, such as the Model Cities and the Ford Foundation "gray area" 
programs, and it provoked extensive controversy regarding the feasibility of designing community service systems (Marris and Rein, 1967).

A related effect of these programs was their dramatization of a paucity of knowledge regarding the organization of human service systems (Warren, 1971). The interorganizational conceptual schemes particularly at the inception of these programs appear in retrospect as shallow and somewhat disjointed. For example, the assumptions underlying the expected consequences of community innovations were shown to be organizationally optimistic and at times even naive (Warren, Rose, and Bergunder, 1974; Sundquist, 1969). Often the strength of existing agency ties was not foreseen (Levine, White, and Vlasak, 1972).

In response to this theoretical lacuna, however, there has recently been a veritable spate of essays on interorganizational relations (see Aldrich, 1976). The accompanying intensification of research has enumerated many of the factors influencing interaction between organizations (see Van de Ven, Emmett, and Koenig (1975). Theoretical perspectives have been elaborated (Aldrich and Pfeffer, 1976). Propositional inventories have been formulated (see, for example, Litwak, 1970). The results of research have accumulated.

Yet this rapid development has also created additional problems and confusion. Integration of theory and research still remains to be accomplished. In attempting to encompass a broad spectrum of institutional life, theorists have frequently chosen quite different variables and levels of analysis as objects of explanation (see Van de Ven, Emmett, and Koenig (1975). The conceptualization and measurement of 
such commonly used variables as "domain" or resources" can differ wide1y. (contrast Thompson, 1967, and Warren, Rose, and Bergunder, 1974). The sheer diversity of organizations asks for differentiation.

In short, a distillation of concepts and orientations is in order. The various emphases in the literature deserve clarification and assessment.

The purpose of this paper is to explore the basis for such a distillation. The tack taken is to classify the contexts of interorganizational activity by employing Warren's (1967) notion of interorganizational fields. Prevalent hypotheses in the literature can then be investigated, using data on interagency relationships in a social service federation.

This empirical examination explores the differentiation of interorganizational concepts according to the "field" of activity. If the interorganizational field level of analysis is found to facilitate theory construction, suggestions for developing Warren's typology into a model will be offered. This design can be clarified by briefly considering different levels of analysis (see Hall and Clark, 1975). An organizational field refers to certain patterns or contexts of organizations within which they negotiate or compete to accomplish their goals. Warren proposes that characteristics of these contexts will affect the behavior of organizations within them. Put abstractly, his proposal is that the properties of a group of organizations exert independent effects; they cannot be reduced to characteristics of the organizations themselves.

Warren thus raises two issues of theory construction pertinent to 
assessing the level of analysis required for understanding relations between organizations. First, if the interorganizational field level significantly influences organizational actions, then research can be designed to discern the degree of these effects. Here knowledge gained by measuring the contexts of relationships can exist in addition to the contributions of organizational or environmental level variables. Speaking statistically, the total "variance explained" would be increased because the effects can be added together.

Second, it is crucial to determine the nature of relationships with a dependent variable. Here the interorganizational field level can be important by limiting or enhancing the relationships of other "independent" variables with this dependent variable. For example, the context or field of the interaction can be an "antecedent" causal factor which must be taken into account. Thus, if a variable were considered across a diversity of contexts, its effects upon other variables might fluctuate significantly; curvilinear relationships or "interaction effects" may emerge. In fact, recent research indicates that the interorganizational field level of analysis overrides the relevance of many variables previously touted as important (see Warren, Rose, and Bergunder, 1974).

In either case interorganizational models would benefit by considering the context of relationships. On the one hand, variables measuring interorganizational fields can be sufficient in explaining such activity. Perhaps more important, they can actually be necessary for understanding interorganizational relationships.

After noting the distinctiveness of the interorganizational level 
of analysis, the remainder of this chapter discusses the interorganizational field typology and its relation to the theory construction purposes of this paper. The second chapter outlines two basic approaches to the interorganizational literature. This review highlights the prominence of certain variables around which a typology of hypotheses is derived for later comparison with data from the case study. The third chapter consists of a discussion of the case study methodology to be employed as well as particular methodological problems accruing to the study of relations between organizations. After the findings of the study are presented, a concluding chapter proposes a theoretical framework for new hypotheses and areas for future research.

Towards an Interorganizational Perspective

The current conceptual schemes on relations between organizations evolved in part from a concern with applying organizational analysis to community service and policy issues. Interagency coordination, for instance, was considered important to the various levels and sectors of community functioning (see Johns and DeMarche, 1951; for an insightful case study on one community ${ }^{r} \mathrm{~s}$ efforts at coordinating service departments, see Mott, 1968). This increasing interest in community planning was joined over time by concern with coordination between levels of government, such as the federalism of the past decade (see Sundquist, 1969, for an overview of this approach; for a distinctive twist to these issues, see Lindbloom, 1965).

Broadly stated, this early approach appeared to emanate from the human relations school in the organizational literature (see Hall, 1972: 
Chapter One), in that it considered community agencies as essentially cooperative collectives (White, 1972). Generally, the early tendency was to accept organizational goals as those expressed publicly by the organization. [For human service agencies, including especially the health and welfare sector, this approach meshed conveniently with a philanthropic ideology; since these organizations would be responsive if they could to the need for coordinative efforts, the theoretical problem therefore was phrased to assume the existence of systematic barriers to cooperation itself. Thus:

lack of mutual knowledge among the organizations was alleged to be the main barrier; the solution therefore called for mechanisms to encourage communication among the organizations regarding their respectives needs and resources...Sensitization of each organization in the given community to the problems of each of the other organizations was the proposed vehicle and mutual understanding the anticipated solution. (Levine, White, and Vlasak, 1972).1

This early emphasis on communication and cooperation between organizations can still be occasionally recognized, as Aldrich has asserted, in the implicit assumption in much of the literature that interorganizational relations are "beneficial," especially from a social engineering perspective. ${ }^{2}$ It is thought that research on inter-

${ }^{1}$ Warren has noted that the dominant, if unstated, ideology in community planning, and by implication interorganizational analysis, is based upon an underlying liberal, "consensus" model (1971); see a1so Warren, Rose, and Bergunder, 1974. It would appear that as long as community service problems are associated with "uncoordinated" services, his charge continues to be relevant.

2 The conflict perspective, of course, takes exception with much of this literature's emphasis. Unfortunately, this perspective has not been clearly extended to interorganizational relations, save for Litwak and Hylton's (1962) contentions about "partial conflict." For possible exceptions, see Howard Aldrich, 1972a and Litwak, 1970. 
organizational relations can tap the opportunity of providing "better" services to clients with less duplication of effort and therefore fewer resources invested. Given the implication that only interagency cooperation was involved, the policy issue became how to make decisions which will yield "a higher aggregate utility than the market" (Warren, 1971:166).

More writers are now taking exception to these possibilities. First, from a social policy perspective, the coordination of social agencies in the pursuit of more effective service delivery is often said to be fraught with dilemmas (see Marris and Rein, 1967; and Gilbert and Specht, 1974; also, Levine, White, and Vlasak, 1972). For example, as the "coordination" between service agencies increases, clients can find the service sector more monolithic and less accountable to their needs.

Second, some claim that adopting a more theoretical point of view assists in systematically probing other pertinent factors. For instance, Litwak posits that the development of interorganizational theory requires broader, social organization perspective. He emphasizes that it is a lack of centralized authority in relations between organizations which is a crucial characteristic, that in fact it is precisely their lack of coordination which can make these relations distinctive from intraorganizational analysis (Litwak and Hylton, 1962; Litwak, 1970). As evidence he cites the political theory of "checks and balances," which holds that there are governmental processes which are different from each other and which stem from discrepant goals which must be preserved (1970:141). Similarly, the 
preservation of the freedoms of religion and the press is given more stability by being housed in organizational structures separate from the government. Finally, and most obviously, some forms of "coordination" in the economic sector can bring charges of "collusion" or "price-fixing," with very different connotations than are usually attributed to similar activities among human service and professional organizations (White, 1972).

Burton Clark (1972:363-66) supports this distinction between the interorganizational and the organizational or "bureaucratic" patterns of activity. By comparing some of their characteristics, he illustrates the contribution of a more interorganizational focus. Decisionmaking within an organization regarding basic goals and policies, for instance, is rather deliberate and purposeful; in fact, organizational structure and hierarchy are presumably designed "rationally" to support such activity. By contrast, the transactions between organizations are much less formally and overtly determined. In addition, an organization's standards of work can be deliberately set, such as through inspections or work codes. Standards between organizations, however, are usually more indirectly or manipulatively established, such as through according prestige, marketplace transactions, or legal precedents (see Perrow, 1961):

Like Litwak and Hylton, Clark gives particular attention to the lack of centralized authority in the interorganizational arena. Here responsibilities are more emergent than delegated, more horizontally agreed upon than vertically designated. Although accountability may be contractually bound, there is nevertheless a voluntary and nego- 
tiated character to the transactions.

Yet these writers recognize that organizations do engage in collaborative relations with each other, and indeed that these interactions can take a variety of forms. In fact, Clark advocates research in developing a theory of confederative organization or "organizational alliance." He specifically urges a focus upon different authority relations, including how organizations can unite their efforts "without the authority of formal hierarchy and employee status" (Clark, 1972: 363).

A Typology of Interorganizational Fields - Prospects

Roland Warren (1967) synthesizes Clark's recommendations with Emery and Trist's (1965) notion of "causal texture" as the basis for his typology of interorganizational "fields." Warren proposed that the contexts of organizations shape and influence their interactions. "The concept of interorganizational field is based on the observation that the interaction between two organizations is affected, in part at least, by the nature of the organizational pattern or network within which they find themselves (Warren, 1967). His particular focus was upon the patterns that could affect the integration or coordination of activities of different organizations. For example, relationships can be mediated by various "structures," such as by laws, adjudicating bodies, or other organizations, and the organizations involved can respond depending upon the type of mediative arrangement.

Warren delineated a typology of four types of fields. These include the unitary, federative, coalitional, and social choice fields. Each field is defined by a particular clustering of six interorganiza- 
tional dimensions. These are: the relation of units to an inclusive goal; locus of inclusive decision-making; locus of authority; structural provisions for division of 1 abor; commitment to a leadership subsystem; and prescribed collectivity orientation of units $(1971: 184-188)$.

The unitary field most closely approximates the structures of a complex organization and is exemplified by a county's health or welfare department. Its units are hierarchically organized so as to facilitate central decision-making. The units work towards designated goals under a prescribed division of 1abor. Moreover, a relatively high "commitment" by the units towards the central leadership is often insured by legal arrangements.

The federative field, as found in a council of service agencies, also features some formal authority organized to achieve certain goals, although ultimately the federation depends on the assent of its constituent organizations. The participating organizations have more autonomy than in a unitary field, and maintain their own charters and goals which frequently encompass more than just their relations with the federation. There is some designated leadership, including formal staff, which supervises decision-making and insures communication between the units. However, the units themselves have some control regarding the extent of authority of this leadership, and their autonomy includes a voice over the division of labor among the agencies. There is a moderate degree of collectivity orientation and commitment to the leadership.

The coalitional field features a group of organizations collab- 
orating more or less closely to achieve singular goals, such as community organizations impermanently banding together to ward off proposed highways or urban renewal projects. Decision-making is much more ad hoc, usually with no formal designation of staff or central authority. The units are predominantly concerned with their own goals and exercise much autonomy in their participation, but are oriented toward the collectivity and its leaders, and a possible loose division of labor, but only insofar as the particular objective is concerned.

Finally, the social choice field, which is best exemplified by the marketplace metaphor, features the autonomous, individuallyoriented behavior of a sector or cluster of organizations. Their participation in this arena can entail discordant goals, although there can be broad legal and normative boundaries regulating their interaction. Since participation in this arena often entails discordant goals, planning or coordinated efforts between organizations proceed at a much smaller scale relative to the other fields.

Warren's differentiation of interorganizational fields was derived from two related but distinct concerns. First, emanating from his research on the community and on what he terms "community decision organizations," he was interested in the applied prospects for "concerted" community planning and service provision. Accordingly, he does not extend his typology to the larger political or economic "field of events" (see Emery and Trist, 1965); instead, it was limited to differentiating the more immediate contextual dimensions of interaction between organizations. Here his stated concern was how a community "satisfies" the different values represented by its different organiza- 
tions.

His second interest, and the one of more concern to this paper, was on generating theory and research. For example, he asserts certain basic propositions about the nature and effects of interorganizational fields. "The concept of interorganizational field is based on the observation that the interaction between two organizations is affected, in part at least, by the nature of the organizational pattern or network within which they find themselves." (Warren, 1971:180) Similarly, he speculates that the shifts between these four fields "can relate different types of actors in new modes of interaction" (1971:181; emphasis not in the original).

If we look broadly at this schema, it becomes evident that Warren is offering dual propositions. First, the conditions for interorganizational relations can be separated into identifiable, coherent clusters of dimensions which vary together and in an ordinal direction. Second, each "cluster" constitutes a distinctive contingency for shaping relations between organizations. Interactions themselves can be changed by the field in which they occur.

Moreover, support can be found for both of these notions. Regarding the first, both Litwak (1970) and Reid (1969; 1964) differentiated between situations of "unmediated" coordination, where as in the social choice field, two or more agencies interact through their own efforts without the intervention or direct regulation of another agency which would be "mediated" coordination similar to a federation or unitary context. Regarding the second suggestion, Aldrich (1976) found in a study of manpower agencies and employment services that the manipula- 
tion of authority relations--a key dimension in Warren's typology-does have an effect, including more intense interaction and more imbalance of referrals. Hall and Clark (1975) also observe that the authority of a legal mandate is important, for it affects the nature and degree of exchange between agencies.

The implication of Warren's suggestions is that interorganizational theory must be constructed with explicit consideration for the field of interaction. The salience or effects of a variable can differ from field to field. For example, the process of exchange between organizations can be highly visible in a social choice, or unmediated context (Levine and White, 1961). However, exchange may be much less conspicuous, even inoperative, where relationships are legally established, as with some unitary contexts.

If different interorganizational concepts can be shown to vary in their applicability between fields, interorganizational theory must accommodate these developments. If patterns can be discerned regarding which of these concepts vary, the evidence for rethinking interorganizational theory becomes even clearer. Indeed, the following chapter constructs a typology for distinguishing between patterns of relationships which may vary.

If the possibilities can be found, at the least, greater attention will be necessary for specifying the scope conditions of propositions. Eventually more encompassing models can be derived which incorporate differences between contexts of interaction. However, preliminary to these ends, certain difficulties can be noted with the interorganizational field typology which provide additional direction 
for deriving a model.

The Interorganizational Field - Problems

Unfortunately, warren does not elaborate upon these ramifications of his typology. The theory construction possibilities just discussed are implicit and not explicit in his writing. First, no justifications are offered that the dimensions of his typology are definitive or exhaustive. Similarly, he hedges on whether the dimensions must necessarily vary together to define a context. Thus, which field a cluster of organizations should be classified under is nebulous when, for example, they manifest some commitment towards a collectivity or collusion but have no division of labor or other structural characteristics of a federation.

Warren himself observes other ambiguities. The unit of analysis, or field, may be difficult to discern operationally. Any given context refers not simply to all organizations in a locality but to a definable cluster of organizations. Thus, the respective "community decision organizations" upon which Warren focuses can themselves be nuclei for their own (frequently unitary) interorganizational fields, yet when interacting with each other they manifest the characteristics of a coalition or social choice field.

A more formidable problem involves specifying what phenomena these contexts affect. Although he suggests that these fields "can relate different types of actors in new modes of interaction," he does not specify what these modes are. Instead, the fields are distinctive simply because their aggregate effects are different.

Finally, the typology suffers from a static conceptualization. 
The nature of the causal factors remains nebulous. No mention is made of interorganizational processes or of the development or institutionalization of a field over time. Ironically, the term "field" itself was borrowed from Mannheim (as referenced in Emery and Trist, 1965), al1 of whom emphasized social change and environmental fluctuations as germane to analyzing relations between organizations.

Given these considerations the interorganizational field schema requires further theoretical clarification. As it stands it is a typology and not a model, and thus it cannot be "tested" in a strict, explanatory sense. We have noted its implicit propositions regarding, first, the dimensions of interorganizational fields, and second, the varying effects of different contexts. However, both the nature and consequences of these effects must be specified if a model is to emerge. Predictive utility requires the specification of the causal elements.

However, if these contextual effects can be specified, the notion of interorganizational fields bears salvaging. Indirectly, Warren is offering a critique of models which fail to consider the effects of interorganizational contexts. Because it differentiates between contexts, his typology is pertinent to the issues previously discussed, namely, distinguishing levels of analysis and building upon other theories of relations between organizations. It would have greater utility if it could classify and examine interorganizational phenomena.

In other words, we want to explore what these contextual effects areby discerning those phenomena to which a model of interorganizational 
fields is relevant. We will not elaborate upon Warren's second proposition about the relevance of the dimensions of these fields. To do so would require a comparative study across a variety of contexts. Instead we will examine one group of organizations which approximates Warren's criteria of a federation.

The next section constructs a classification scheme for exploring and elaborating upon the interorganizational field typology. An integration of perspectives in a literature has produced four theoretical subareas. Through a case study of a social service federation, the relevance of Warren's typology to these sub-areas can be empirically examined. 


\section{CHAPTER II}

\section{APPROACHES TO INTERORGANIZATIONAL RELATIONSHIPS}

This chapter reviews the interorganizational literature in order to cull prevalent but diverse propositions about relations between organizations. With the selection of these kinds of propositions, a theoretically more complete and rigorous assessment of any differences between interorganizational fields is possible. These propositions can then be empirically examined to ferret out which phenomena are most affected by the context of the relationships.

Although interorganizational relations have been conceptualized in various ways (see Tropman, 1974; Marrett,1971), a large portion of the literature can be subsumed under two approaches. 3 Perhaps more precisely regarded as units of analysis, between them they parsimoniously capture dominant orientations in interorganizational theory. The first is organization-centered and emphasizes the characteristics of organizations as resource seeking and as maintaining technologies which yield particular outputs. Given these characteristics organizations attempt to adapt to (and change) their environment (see Thompson, 1967). The second is relational and focuses upon a group or cluster

${ }^{3} \mathrm{~A}$ third unit of analysis can be noted which focuses more exclusively upon the characteristics of organizational environments. Thus, Emery and Trist (1965) and Terreberry (1968) discuss the evolution of the causal texture of environments, Aldrich and Pfeffer (1976) discuss the "natural selection" model of environments, and Benson (1975) considers the political economy as a broad context for interorganizational networks. This approach will not be integrated into this discussion. 
of organizations. It is concerned primarily with the structure and the linkage between organizations (see Litwak, 1970; and Morrissey, Horan, and Rieker, 1975).

This chapter indicates how these approaches overlap in substantive matters. In fact, the intersection of their dimensions potentially represents a demarcation of four subareas which taken together represent a significant portion of the literature. Although the two approaches sometimes differ in analysis of interorganizational phenomena, their integration in this manner may assist in building a model of interorganizational fields by sorting out differences in contextual effects. That is, the typology which results from integrating the organizational-centered and relational approaches may facilitate providing explanations regarding why the field or context affects interaction.

The Organization-Centered Approach

This tack takes as its unit of analysis the organization itself. Its focus is upon how the environment of the organization can impose itself as a contingency or constraint upon the organization's activities. More specifically, this approach extends the open systems theory on complex organizations to construct a picture of interorganizational relations more or less as input-output activities (see Morrissey, Horan, and Rieker, 1975; a1so, Warren, 1971:173; Aldrich, 1972a, and Dill, 1962 and 1958). Thompson, who articulates this approach most systematically (1967:1-10), begins with the proposal that organizations attempt to maintain a "rational" structure, that is, a structure calculated to achieve certain goals and "produce results" 
(1967:1). Assuming this, we first discuss general characteristics of the interaction of organizations and environments and next note two dimensions central to this interaction.

Thompson asserted that it is "uncertainty" which constitutes a major threat to organizational rationality. Specifically, the organization's environment presents itself as a basic source of this uncertainty (Thompson, 1967:1). In this vein Aldrich (1972a)listed seven aspects of organizational environments which can have an impact upon the functioning of the organization. These included: stability, or degree of turnover among elements in the environment (such as with 'raw materials or other organizations); homogeneity, or degree of similarity between the elements of the population dealt with; and environmental "capacity," or the extent of resources available with an organization's domain.

Each of these seven aspects can affect organizational performance. A stable environment allows the organization to establish a more centralized structure (Lawrence and Lorsch, 1967; Thompson, 1967; Aiken and Hage, 1968; Simpson and Gulley, 1962). Note, however, that the more fixed the structure of the organization, the more susceptible it is to fluctuations in the environment. Similarly, a homogeneous environment, which in the case of service organizations includes the characteristics of clients, can facilitate the development of a standardized treatment or output technology (Aldrich, 1972b; Litwak and Hylton, 1962). Finally, the more resources in the environment, the more alternatives are available to the organization in achieving its goals, which in turn affects the necessity for interacting with other 
organizations (Levine and White, 1961; Levine, White and Vlasak, 1972).

In response to a problematic environment, an organization has at least two alternatives for action. First, there is the modification of organizational goals, or "goal-setting" (Thompson and McEwen, (1958), as perhaps in response to changing markets, domains, or even as a result of successes in achieving past goals. Second, organizations can modify their structure so as to buffer their technology against the environment (Thompson, 1967). Thus, Lawrence and Lorsch (1967) found that a greater degree of departmental differentiation and autonomy under circumstances of rapid environmental flux was correlated with organizatioan1 "success."

These responses to uncertainty can be better understood by probing two particular dimensions of organizations. First, they typically have some kind of technology. This concept broadly includes the mechanisms, procedures, and expertise involved in producing a particular outcome. For human service organizations these outcomes can vary from resocializing clients to providing welfare checks to "peopleprocessing" (Hasenfeld, 1972). Thus, the technology for these outcomes includes the procedures for conducting therapy groups, the certification procedures of welfare organizations, and the "professional judgment" and expertise involved in referring clients.

The second dimension is that of the resources required by the organization to conduct its business satisfactorily. We are using the concept of resources here in a broad sense to include also certain intangible and qualitative aspects, such as the organization's prestige (Clark, 1972) or the information required to yield results or 
upgrade its technoiogy (Aldrich, 1972b; Reid, 1969:177). Thus, besides money and material, the resources dimension encompasses the notion of organizational "domain," or its legitimate sphere of activity as consented to by the public and other organizations (Levine and White, 1961; Braito, Paulson, and Klong1on, 1972). ${ }^{4}$

For our purposes both technology and resources are vitally and inevitably linked to interorganizational relations. Regarding resources, for example, the goals of a health agency require the acquisition of the clients and labor services (input) necessary to fulfill its output functions (see Thompson, 1967:16). However, it can "seldom carry out even these (functions) without, to some extent at least, cooperating and establishing relationships with other agencies in the health and welfare world" (Levine, White, and Paul, 1963:165). Thus, Warren, observes that an organization is typically concerned with preserving or even expanding its domain (Warren, Rose, and Bergunder, 1974; see also Parsons, as referenced in Thompson, 1967:10).

One interorganizational means of obtaining these various resources is through "exchange" (Levine and White, 1961; Tropman, 1974), which can be defined as a process of reciprocally linking with other organi-

${ }^{4}$ Warren (1971:201) includes in the concept of domain both the technological and resource dimensions, focusing more upon these as organizational prerequisites. However, the usage here is restricted so as to be more consistent with the usual meaning of the term denoting a negotiation process between organizations over the activities which they can legitimately conduct. 
zations expressly to acquire resources. ${ }^{5}$ Levine and White describe various aspects of exchange relations, including the substances or resources possibly involved and the status of the negotiations, such as informal versus contractual exchanges. Also important is the "direction" of the transaction, which can be reciprocal (elements flow from one organization in return for elements from the other) or joint (where elements "flow from two organizations acting in unison toward a third" 1961:355).

As outlined by Levine and White, exchange can also include transactions of tangible goods for resources less easily assessed, such as local prestige and a long-term domain. This characteristic of exchange renders the concept difficult to measure or to distinguish from power phenomena. Another consequence is that there can be a discrepancy in the benefits which two organizations have gained through a transaction. For example, the amount of resources already controlled by the organizations makes relative any comparison of gain or loss between them, as Litwak (1970) cogently points out. Finally, this

${ }^{5}$ Levine and White state that organizations desire to preserve autonomy by not entering into relationships, but that exchange in some way is usually unavoidable given that organizations operate under conditions of scarcity of resources (see also Klonglan, Paulson, and Rogers (1972). Litwak (1970) takes issue with this "scarcity hypothesis," maintaining the converse: organizations with more resources will be more likely (up to a point) to enter into exchange relations since they have the requisite resources with which to begin bargaining (see also Melchar and Adamek, 1975). Since the agencies which are studied in this paper are already engaged to some extent in a federative network of relations, we will not examine specifically why or how these particular service agencies entered into relations. Thus, we will avoid the broad proposition that these resources are "necessary" for organizational funding. 
comparison must be gauged over time, as the exchange affects the balance of later transactions. ${ }^{6}$

By implication, an important feature of exchange relations is that they typically entail some costs to the organization (Reid, 1969). The general proposition here is that the rewards of the transaction must equal and preferably outweigh the costs and problems which the association entails. Two particular types of costs, which are interrelated, can be noted.

First, routinized interorganizational exchanges often involve "resource dependency" (Blau, 1964; Aldrich, 1976). This dependency stems from a lack of alternatives in obtaining resources. "An organization is dependent on some element of its task environment (1) in proportion to the organization's need for resources or performance which that element can provide and (2) in inverse proportion to the ability of other elements to provide the same resource or performance"(Thompson, 1967:30). Thus, dependency places the organization in a potentially uncertain environment, one which is less favorable to organizational control (Aldrich, 1972a and 1972b). Moreover, this dependency can occur in both input and output domains, as when an organization finds it difficult to entice enough clients or cannot locate a market for its goods. Thus, to establish a domain, inasmuch as this process depends on organizations in the task environment, an organization must offer

${ }^{6}$ One criticism with the exchange concept, particularly as initially formulated, was that it focused too exclusively upon the inception of interorganizational relations, or the balance of gain and loss at a single point in time, rather than upon what followed the initial transaction or how this balance could be redefined through later transactions. 
something (Braito, Paulson and Klonglon, 1972).

A simultaneous cost of exchange is that the organizations involved tend (especially when very dependent on the relationship) to forego autonomy (Levine, White and Paul, 1963; Klonglon, Paulson, and Rogers, 1972). Autonomy. is broadiy defined as organizational self-direction which is not contingent upon other groups. A generally accepted proposition in the literature is that organizations desire to maximize their autonomy (Gouldner, 1959). However, some autonomy is sacrificed when, under conditions of dependency, an organization is restricted in establishing or modifying its goals (Thompson and McEwen, 1958). For example, autonomy is necessary to maintain the viability of organizational technology; to "place boundaries around those activities which if left to the task environment would be crucial contingencies" (Thompson, 1967:50).

Thus, we return to the second dimension of organizations which affects their interorganizational relations. An organization's technology, including the procedures and expertise utilized in producing outputs, in various ways comes to be interwoven with interorganizational relations. First, as previously noted, an efficient technology requires some buffering from environmental constraints and hazards. Secondly, an organization's technology can importantly influence the nature and extent of its relationships. Thompson notes, for instance, that the structure of the interdependencies between organizations can stem from the admixture of their separate technologies (Thompson, 1967:54). In turn, the type of interdependence affects the type of consequent exchange and dependency relations. 
The type of technology supported by an organization can directly influence relationships in other ways. A large body of literature supports the proposition that the nature of the technology corresponds closely with the degree of task standardization, or changeability of the element to be coordinated. (Perrow, 1972; Hage and Aiken, 1972; Lawrence and Lorsch, 1967). Standardization then becomes a contingency for the linkage between organizations; in fact, Litwak lists it as one of the most significant variables influencing the feasibility of coordination schemes (Litwak and Hylton, 1962; Litwak and Meyer, 1968; Litwak, 1970). He (1970:152) posits that "extremely nonstandardized situations will be best managed by primary-group type linkages, while extremely standardized situations will be handled most effectively by linkages which consist of written rules."

In short, technology helps to differentiate types of organizations and their structures (Perrow, 1972; Azumi, 1972:99). One obvious distinction is between "technical production organizations and human service organizations" (Demone and Harshbarger, 1975 provide a comparison). White treats some of these differences at length:

Integration of the profit-making system is achieved through the linkage of specific dyads of organizations in terms of reciprocal needs and demands. Even though the "system" is pluralistic, it thereby becomes integrated. The vital point is that in this process individual decision-makers adjust or modify their allocations or activities to conform to the requirements of decision-makers in other collectivities (organizations). The resulting complementarity of the activities of dyads of organizations produced system integration. (1972:35).

White goes on to note that among profit-seeking organizations, contracts and monetary exchange facilitate the coordination of relations.

In contrast, money is much less often used to expedite the flow 
of resources among health and welfare organizations. An important corollary of this difference is that this along with the particular technology of human service organizations makes the evaluation of their performance much more problematic. One consequence for public policy is that it is more difficult to hold non-profit rather than profit organizations accountable for what they do or do not accomplish (see Gilbert and Specht, 1974). 7

The difficulties of patterned interaction between human service organizations are thus comparable to a barter situation. "It is precisely because the needs of both the two participating parties must be fulfilled by a single exchange that an integrated and rational system of exchange does not evolve" (Levine, White and Vlasak, 1972). Accordingly, "When the profit criterion cannot be applied, it becomes more difficult to define precisely what an organization is seeking to accomplish and how well it is doing it, and for whom" (Warren, Rose and Bergunder, 1974:7). Zald (1974) notes other dilemmas of integrating services: "though. . a service agency could acquire clients from other.agencies,. . . its managers frequently are accountable to fulfill their organizational goals and ideology, and face a constituency to reinforce these functions."

One final, and significant, technological trait of human service

${ }^{7}$ Ironically, moves to coerce agencies to become more accountable can further the tendency to select "good" clients, that is clients who are more serviceable and thus simultaneously are less of a drain on agency resources and are more likely to be presentable as a public statistic of organizational success. (Levine and White, 1961). 
organizations is that their "raw materials"--clients--can act back upon the organization. Thus, the welfare system has in the past decade experienced the unionization of its clients, at times with consequent modifications in organizational policy. It is this interaction between organization and client that Lefton $(1975: 171)$ suggests is a crucial variable.

The Relational Approach

The organization-centered perspective views the characteristics of interorganizational associations as emanating from the propensities of an organization's resource needs and technological characteristics. It views these associations from the vantage of a single organization.

In contrast, the relational approach asserts that with an aggregate of interacting organizations, the characteristics of the relationships themselves become an appropriate unit of analysis (Benson, 1975). ${ }^{8}$ That is, viewing these interactions simply as extension of an autonomous unit, as influenced by intra-organizational characteristics, is inadequate (Warren, 1972). Instead, phenomena such as power or resource dependence stem from characteristics of the context of relationships.

The interorganizational field typology emanates from this approach. However, the typology and the relational approach have not been adequately integrated, perhaps because neither offers a coherent theory. This section first outlines the general concern of the

${ }^{8}$ The concept of "organization-set" is a possible bridge between the emphases of these two approaches. See Evan (1972) for a definition, and Azumi (1972) and Aldrich (1977) for an extension of this concept. 
relational approach with interdependence and second delineates two dimensions which sharpen the focus of this approach. Although it does not necessarily compete with the organization-centered approach, it does offer alternative explanations pertinent for distinguishing between the effects of different fields.

Early proponents of a relational approach asserted that understanding the conditions for stability, conflict and cooperation requires a concept of "interdependence." (See Litwak and Hylton, 1962). Organizations are interdependent when they are affected by each other's actions (Lauffer, 1974:266; Guetzkow, 1966). For example, decisions about which product to manufacture affects both suppliers and the competing organizations in that market.

However, the generality of this description is fraught with theoretical ambiguities. An elaboration of the numerous facets of interdependence is necessary to reveal whether it contributes to interorganizational conceptualization.

First, any organization will have multiple interdependencies with its environment. It can be involved in more than one interorganizational field. Differentiating the variety of input and output affiliations of an organization begets multiple interdependencies. In addition to suppliers of resources and competitors for products, there are associations for public relations and for providing auspices or funds (Lauffer, 1974). Simply the extent of extra-curricular associations of its members or constituency can increase the organization's network of interactions (see Zald, 1974; also, Mitchel1, 1969). Moreover, there is a distinction bétween horizontal (local) and vertical (national) 
ties (Warren, 1971). Thus, many locally-based organizations, be they churches, medical societies, or commercial dealerships, subsist under the sponsorship of a national affiliate.

Next, interdependence can be distinguished in terms of facilitative and competitive linkages (Litwak, 1970:161-173). Facilitative interdependence indicates that each organization can benefit from collaborating with the other, as where both desire some resource which the other contrals. Competitive interdependency, on the other hand, denotes that the interaction is tinged with threats over resources or markets, though through laws or ethical codes some lines of cooperation are encouraged. Facilitative interdependence is more likely to occur within a federation of organizations; competition is more likely to occur in a setting of social choice relationships.

Another approach to interdependence takes its origin from Durkheim. Explicit in the concepts of mechanical and organic solidarity is a differentiation of interdependence. The former indicates interdependence based on "sameness" or mutuality, such as that emanating from a common outside threat entailing a collective outcome or common goal (La uffer; 1974:267; Tropman, 1974:153; Mott, 1968). Organic interdependence stems from organizations with different but complementary needs with respect to their different resources or goals.

The central proposition linking most of these descriptions is that the extent and quality of the relations between organizations is contingent upon the nature of their interdependence. Thus, if there is no overlap between the goals and tasks of organizations, there is little basis for interacting at al1 (Reid, 1969:177). Under conditions 
of facilitative interdependence, however, coordination between agencies can likely be encouraged through stressing certain modes of communication (Litwak, 1970:163). Final1y, interdependence establishes the conditions of conflict (Reid, 1969). For example, White (1968) describes a case in which a conflict between a local health agency was created when the pressures of its national sponsoring organization catalyzed a rivalry between them.

Despite its contribution, however, there are certain theoretical and methodological problems which remain with the concept of interdependence. First, some above have defined interdependence in terms of "resources" (Lauffer, 1974) while others have emphasized its connection with organizational "goals" (Reid, 1969; Tropman, 1974). Here use of the term seems correlated with how one has defined an "organization." For example, Aldrich (1972a) characterizes interdependence in the context of the variety of resources which an organization typically requires. Reid (1969), in contrast, focuses on goals of the organization as defining the parameters of a conflictive, independent, or cooperative linkage.

Such discrepancies harbor other difficulties. The scope of interdependence is usually not delimited. Although applicability to al1 interorganizational situations is sometimes affirmed, in fact its use has primarily been explored in the context of "getting organizations. together," such as the conditions of the inception or initial coordination of relations (see Reid, 1969; Hage, (1975). Thus, as Hall (1972) notes, the conditions for relations which are already 
institutionalized have been left unattended by researchers. 9

Next, there are problems with noting the duration of interdependence. Over time, and indirectly, most organizations could be considered interdependent relative to the breadth of the analyst's concern, though Litwak (1970:147) does attempt to confine usage more to the "immediate" context of interaction.

Similarly, no "scale" exists for measuring the degree of interdependency between organizations. Its vagueness glimmers in Litwak's (1970) use of the quasi-concept "partial interdependence." Thus, its utility as an independent variable, like the use of the global variable "social," becomes rather contingent upon recognizing other factors. The slippage of this concept is evident in examining an article by Aiken and Hage (1968) on interdependence and organizational structure. At the beginning of the article the concept interdependence refers specifically to relations between organizations, but later it is spoken of as a characteristic of an organization.

Therefore, to rescue it from these ambiguities, the relational approach also can be more adequately described by delineating two dimensions, structure and linkage. The structural dimension refers to morphological arrangements between organizations. It includes the

9 The "scarcity hypothesis" previously mentioned is based, for example, on the inception of interorganizational relations. For recent evidence which seems to counter this hypothesis, see Warren, (1972). Also, in his study of a "coordinating council" of health and welfare agencies, Mott $(1968: 85)$ observes that it was the four larger, more powerful agencies which had the most to gain or to lose, which interacted the most; the smaller agencies, on the other hand, played a less significant role in the proceedings. 
administrative positioning between organizations and those factors such as resources, goals and tasks which affect these positions. The linkage dimension includes the quality or characteristics of the relationships. Thus included is the frequency, standardization, and reciprocity of the interaction (see Marrett, 1971).

Both dimensions share characteristics similar to interdependence. However, they adequately subsume and clarify the types of interdependence while also encompassing other relational characteristics, particularly communication, which are at most implicit with the concept of interdependence.

Both dimensions intersect with concepts already discussed under the organization-environment approach, but do so with an emphasis on relational qualities of interaction. Under the structural dimension organizational autonomy, for example, can be placed in perspective as boundary (or position) maintenance activity (Aldrich, 1972a:283). Here authority or power can refer to gatekeeper control over entry and expulsion of members or clients ("resources").

But in a broader sense, autonomy can be calculated in relation to the organization's network of associations. "To obtain resources, an organization may have to give up its autonomy and enter into a cooperative or amalgamative relationship with another organization. It may have to give up autonomy in one relationship while retaining it in another" (Frey, 1973:10). In this way an organization can, for example, expand its domain, and therefore its autonomy, through its relationships (see Azumi, 1972; Thompson, 1967). Put another way, as Frey shows, there is no necessary correlation between organizational 
control over resources and its dependence upon the environment. In short, autonomy is not simply the inverse of interdependence, nor is it isolation from interaction (for a contrary view see Guetzkow, 1966).

Similarly, an understanding of resource dependency is broadened when viewed through structural lenses, for an organization's alternatives are exercised through its position in a network of relations (Tropman, 1974:156). As Benson succinctly states this proposal for human service agencies, "where network organizations are engaged in multiple, differentiated services to clients, an organization at the center of referral, i.e., one to which all or many clients must be referred, may gain power over those at the periphery. This occurs because centrality makes an organization crucial to the resource acquisition of other agencies." (Benson, 1975). In other words, interorganization "power" is not simply the amount of resources which an organization owns; rather power accrues to position within a network.

The structural dimension also intersects with the more technological aspects of relationships, especially the division of labor among organizations. This includes both the kind of tasks undertaken and the mechanics of efficient production (see Litwak, 1970). Regarding the latter, for example, a task hierarchy between organizations can prescribe the sequencing of work flow and passage of information, but it is inevitably contingent upon the fulfillment of task responsibilities. Most theorists appear to assert that the more this division of labor is so specified, the greater the interdependence and stability of the network. (Reid, 1969; for an alternative view, see Pondy, 1967:318). 
The nature of tasks which an organization undertakes, in turn, requires that it establish its task domain. This negotiation can be more or less problematic depending upon, for example, the goals of the other organizations. Complementary goals can facilitate a stable basis for organizational transaction (Evan, 1972; Aiken and Hage, 1968; Reid, 1969).

The linkage dimension focuses more specifically upon the features and substance of the relationship itself. First, it intersects with an organization's technology in that the type of task is inevitably related to the characteristics of linkages (Litwak and Hylton, 1962). As previously discussed, the nature of the communication required can affect interorganizational patterns; more non-routine cases may need greater face-to-face, idiosyncratic coordiation (see also Hage and Aiken, 1972) .

Second, the linkage dimension can also refine an understanding of "resources." First, it would seem that interorganizational relations develop a normative basis just as do interpersonal relations; in fact, Pondy (1967) lists norms as a basis for interdependence (see also Aiken and Alford, 1970; and Guetzkow, 1966). Warren's concept of "institutionalized thought structure" (1974:22-23) is pertinent here, for it implies that over time certain implicit rules or justifications become built up, forming a background for interaction. His preliminary research indicates that this normative structure "serves to reduce uncertainty to controllable dimensions, to minimize contest, to resist change, and to assure organizational viability" (1972:157). Indeed, similar research by Rose (1973) details how organizations can appeal 
to this normative order. His study of community action agencies documented the process by which the goals of encroaching organizations can be coopted as they become assimilated into the network of community agencies.

In a related manner, this intersection between linkage characteristics and resources suggests a reconsideration of "exchange" relationships. Exchange often implies a somewhat tenuous type of barter requiring an ongoing, reciprocal resettlement of terms (Levine, White, and Vlasak, 1972). It is thereby affected by the normative element of associations. However, this meaning of exchange is not germane to the structural dimension. It does not encompass the more routinized, even mechanical transactions which often occur between organizations. In this respect, Hall (1972) states that interactions which are legally required or which are highly formalized may not require barter or bargaining, especially once a "precedent" for interaction is established.

Examining Interorganizational Fields: A Typology and Hypotheses

The substantive overlap between these two approaches should be apparent. The intersection of their dimensions results in a typology of four distinct activity areas as depicted in Figure 1. These cells can be labeled to organize their comparison across interorganizational fields. Cell A can be termed the transactional subarea and represents the intersection of the linkage and resource dimensions. It thereby encompasses both the relational nature of resources, including their normative characteristics, and the processes of acquiring and exchanging resources. 
Relational Approach:

Linkage

Properties
Structural

Properties

\begin{tabular}{ll|l|l|}
$\begin{array}{l}\text { Organization } \\
\text { Centered } \\
\text { Approach: }\end{array}$ & Resources & A. Transactional & B. Managerial \\
\cline { 2 - 3 } & C. Communication & $\begin{array}{l}\text { D. Division of } \\
\text { Labor }\end{array}$ \\
\hline
\end{tabular}

Figure 1. Four subareas of interorganizational relations.

Ce11 B represents what we can call the managerial subarea. It likewise features the resource dimension as it intersects with the structure of relationships. It includes the managerial strategies which organizations use to protect their autonomy and to establish their position in the interorganizational network.

Next, a combination of the linkage and technological dimensions yields cell C, as broadly categorized by "communication." This cell concerns those kinds of linkage characteristics, such as standardization of task and coordination through inter-agency conferences, which bear upon accomplishing a goal.

Finally, cell D,which can be labeled the division of labor subarea, is created by the technological and structural dimensions. At focus here is the mesh of the respective goals of the participating organizations and its interaction with the administrative "positioning" of organizations to achieve (more or less) common goals.

This typology can be useful in constructing a model of interorganizational fields. First, by demarcating these subareas it facilitates probing the nature of any contextual effects between fields. Empirical exploration with a case study can be less selective or arbitrary because the typology encompasses much of the literature on 
relations between organizations.

Second, by integrating these two approaches, alternative hypotheses about the effects of interorganizational contexts can be germinated.

The relational approach suggests that organizations "exist and take their form within an interorganizational context" (Warren, 1972), while a focus upon organizational characteristics helps differentiate the nature of the interdependencies which can emerge (Thompson, 1967). Because they are more precisely units of analysis and not mutually exclusive "theories," an examination of their content areas can suggest where conceptual ties lie.

From this literature review hypotheses can be extracted which represent dominant lines of thought for each subarea. These hypotheses are paraphrased from key articles; each has been proposed or implied in at least two sources.

HYPOTHESIS 1: THE TRANSACTIONAL SUBAREA

The larger the amounts of resources at stake in the relationships between organizations, the more the transactions will be characterized by reciprocity. (Levine and White, 1961; Marrett, 1971).

HYPOTHESIS 2: THE MANAGERIAL SUBAREA

The more dependent Organization $A$ is upon the resources of Organization B, the more Organization A seeks to develop (input and output) relationships with organizations C, D, and/or E. (Aldrich, 1976; Thompson, 1967).

HYPOTHESIS 3: THE COMMUNICATION SUBAREA

Characteristics of the production process determine those forms of interorganizational communication which will be most effective. (Litwak, 1970; Lawrence and Lorsch., 1967).

HYPOTHESIS 4; THE DIVISION OF LABOR SUBAREA

The greater the (facilitative) interdependency of relationships, the greater the stability of the transactions. (Litwak, 1970; Reid, 1969; Hage, 1975). 
These four hypotheses will guide our case study of a social service federation. They were chosen first, because they are prevalent in the literature, and second, because they capture the diversity of interorganizational phenomena by integrating the relational and organization-centered approaches. In other words, between them the hypotheses permit a broad investigation of interorganizational fields. Because they differentiate many aspects of interorganizational relations, the hypotheses can facilitate the specification of the effects of different fields or contexts. In short, if the predicted relationships are not borne out empirically, the assertion of contextual differences takes on greater credence.

Contextual Effects of Federations: Alternative Conceptualizations

However, simply to find invalid the four hypotheses just delineated is not necessarily a significant advance. Although such findings would indicate the need for additional theory and research, the implications would be largely residual. Rather, alternative conceptualizations are necessary to detect any contextual effects for this federation. Though relatively little of the interorganizational literature has probed the differences between fields, there is a modicum of support for alternative hypotheses. These alternatives can be briefly sketched.

First, regarding the reciprocity hypothesis, various reasons have been suggested why exchange processes might be less prominent in a federation. Direct exchange between two agencies may simply not be necessary for interaction. Exchange formulations seem particularly relevant concerning the instigation of relationships, but may be less 
important for an ongoing relationship or where the relationship is mandated by law (Melchar and Adamek, 1975; Hall and Clark, 1975). Here calculation by representatives of an organization of whether to initiate the relationship becomes less problematic.

Instead, in a federation "rational" calculation of rewards and costs of any one relationship is encased in overall outcomes of participation. The gain from participation can be less immediate or tangible than exchanges in a social choice field (Davidson, 1976). An agency may receive few direct benefits from a particular relationship but may endure it because inclusion in the federation requires it.

The hypothesis about resource dependency might also be affected by the federative context. As with reciprocity, the calculation of dependency for an organization within a federation becomes more complex because all organizations must be considered at once. The agencies in the federation become alternatives for relationships. This calculation is more complex because in this case the administrative component can mediate the importance of dependency. For both of these reasons--the more alternative relationships present and the mediation of power--the federation can provide a source of environmental stability (Pfeffer and Leong, 1977).

Regarding the hypothesis about the nature of the production process and communication within the federation, an alternative formulation is that the federation can facilitate the production process through its division of 1 abor and overall increased communication. In this way interagency procedures can become more defined and patterned, thereby lessening the importance of standardization. 
Finally, interdependency can in some contexts be detrimental to the stability of relationships. Though a division of labor defines the pattern of relations, various people point out that interdependence can become too rigorous, too inflexible to permit adaptation to changing internal or external circumstances (Gouldner, 1959; Pondy, 1967; Aldrich, 1977). This may especially be the case where transactions between agencies are rather unstandardized.

In sum, in this chapter we have extracted two approaches and four hypotheses prevalent in the interorganizational literature. We have also formulated alternative conceptualizations regarding why these hypotheses might apply to some contexts but not adequately account for behavior within a federative field. This literature review is preliminary to an empirical examination of a federation which can at once function as a critique of this literature and as a probe for contextual effects. 


\section{CHAPTER III}

\section{THE FEDERATION OF SERVICE AGENCIES}

This chapter introduces the federation of social service agencies selected for this study. We describe characteristics of the "sample" of these organizations and specify the criteria of selecting them for study. We will also justify the applicability of their relationship for the interorganizational field level of analysis.

\section{A Multiorganizational Service Project}

The focus of the federative umbrella was a two-year service project and its network of inter-agency relations. The agencies involved were participants in a local and state-supported attempt in a large metropolitan community in the Pacific Northwest to coordinate the delivery of particular services. This project was actually a two year demonstration project designed in conjunction with federal agencies to test whether local agencies could effectively coordinate on such a project with minimal administration. With some exceptions these agencies had not maintained extensive relationships with each other prior to the project, and indeed some agencies had existed for only a few years or months. However, though this project itself was slated for a two year tenure, the agencies involved knew that there was a likely prospect of continued government funding and that the level of funding could depend upon the effectiveness of this demonstration project. 
The designated clientele, or "target population," of these efforts were those elderly perceived as having problems of sufficient severity as to threaten their independent living. The broader service goal was actually to deliver and expedite available community services which assisted the ability of these elderly to live in the community. 10 Approximately 400 clients a month were provided these services by project agencies alone.

Of the organizations affiliated in any manner with this project, nine agencies, and the design or "system" of relationships between them, comprise the focus of this study. Each of these, and its function within the federation, will now be briefly discussed.

The first organization to be discussed is the "administrative component" of the project. Adhering ultimately to policies established by a board of directors and the local and state commissions on aging, this agency and its project director were responsible for managing project coordination and smoothing the day-to-day ruffles of service delivery. The agency also promoted project goals in the larger community, acting as a liaison especially to other services for the elderly.

Next, an agency which can be entitled "protective services" was assigned an assortment of liaison services for clients in need of counseling, psychiatric, or medical assistance. Housed in the county mental health department, it was composed at various times in the project's history of from three to six social workers and service aides

${ }^{10}$ This overview is obtained from the project's "First Annual Report," as prepared by the evaluation component of the project. 
who operated closely with other community organizations.

The project's "legal component" worked predominantly as a consultant to protect the legal interests of clients and represent them in various official matters. Affiliated with a local legal aid agency, this component consisted of a lawyer, her staff, and some volunteer and consultation assistance.

The project also featured the delivery of more immediate, tangible services. Its "homemaker component," a wing of a locally wel1known family counseling agency, provided housekeeping and personal home care for clients, and assisted as well with their "case planning." This component included a team of homemakers, a supervisor and a social worker.

Direct services were also provided by the "nutrition component." This was an independent agency which, by sponsoring dining sites across the city, both established facilities for congregate dining and actually delivered meals to the homes of immobilized clients.

Finally, four separate organizations functioned under the title of "referral component." Geographically distributed in different sections of the city, the responsibilities of these organizations varied more markedly during the project's tenure. Generally, however, the duties of the paraprofessionals at these agencies included locating eligible clients, determining their particular service needs for appropriate referral, and insuring the completion of their referrals. Moreoyer, at each of these organizations transportation resources were stationed (particularly during the first project year) to assist clients in meeting referrals and other appointments. 
A brief appraisal of the role of the administrative component on the interagency scheme is pertinent at this point. An examination readily reveals its "mediating" effects. Although the administrative head of the project's coordination was unavoidably encumbered, particularly during the first operating year, with broader planning and community organization activities, he nevertheless devoted substantial time to general supervision and to meeting with the contracted agencies. Other administrative personnel had more specialized responsibilities, including supervision of referral agency workers and establishing the procedures for the project's intake of clients. These people also worked closely with the evaluation component of the project to formulate a standardized set of criteria for defining client characteristics and thereby restricting entry into the arena of services.

The interviews with officials from the contracted agencies indicate the extent to which this administrative component demarcated interagency roles. All but one of the agency administrators interviewed felt that, except for a few contrary instances, there had been adequate communication with them about their position in the project. There were a few more negative reflections about the communication of ongoing project developments, but again a clear majority of officials considered administrative feedback to be adequate. Moreover, the administratiye component had an indirect effect by encouraging and sponsoring conferences of all types between agencies.

Finally, project records verify that the administrative component (in conjunction with authorization from state and local granting 
delegations) worked to establish the basic interorganizationalreferral design of the project. Interview data revealed that when various service exigencies in the original design proved unwieldly, this component assisted in facilitating a less problematic scheme. These interviews also revealed that when the sheer bulk of clients threatened to bog down interagency processes, this component was instrumental in restricting client intake and clarifying which agencies might at any time have "responsibility" for a client.

Therefore, we may conclude that these interorganizational relations were "mediated" by this coordinating component. That is, it did have an effect in shaping the structure of relationships, and it was a significant protagonist in altering the patterns of authority and domain between agencies.

The associations between these nine organizations constitute by Warren's typology a definably federative cluster of interrelationships. There is an authority structure which upholds a division of labor to achieve certain common goals. Moreover, the participating organizations did affirm the necessity of some joint commitment to serve their elderly clientele.

At the same time these organizations did have considerable autonomy, as was made evident in interviews with various agency officials regarding their role in the shift in the federation's sérvice design. Even though three agencies--one from the referral, and one each from the legal and the protective service components--were hired to participate in the project, all agencies featured organizational characteristics, as this term is usually used, 
regardless of their frequently small size. That is, each had distinctive positions and perspectives within the federation, and was capable of acting independently of the other components. Some were affiliated with larger organizations, but in no way were they branches of each other.

Besides correspondence with the previously described characteristics of a federation, certain other criteria were used in delimiting this focal set of organizations. First, only organizations contracted for service activity or direct administration were selected for study. Although various community agencies participated frequently with project tasks, those other than the nine had no formal service roles. Thereby excluded are personnel minimally contracted for liaison with other agencies as well as the project's evaluation component, which performed an indirect information function. For similar reasons, the state and the local commissions on aging are also not examined.

In sum, these nine organizations and their relationships constitute a federative arrangement. As such it can justifiably be compared with the hypotheses listed in the previous chapter. Thus this case study provides an opportunity for examining the importance of Warren's concept of interorganizational fields.

There are, however, certain influencing factors which we should consider in our analysis. Besides the normative, non-profit characteristics, many of these organizations are rather small, and this variable of size can differentiate certain interactional qualities (Simpson and Gulley, 1962). One might anticipate, for instance, that interorganizational awareness and the "primary group" characteristics of interaction 
would be heightened by this factor. Moreover, the size of the central network itself is rather small and this would have an impact upon the nature of the coordinating devices feasible (Litwak and Hylton, 1962). Organizational "age" is another factor which must be considered. Some posit that the length of an organization's operation is related to its characteristics. The literature is inconclusive on this point, however; Rosengren (1968) suggests that new, action-oriented organizations are less likely to feel a functional need to engage in interorganizational relations, but Zald (1974) feels that such organizations would be less committed to a particular community network and therefore would be less constricted by older ties. Regarding this point, records and interviews indicated few associations between these nine organizations prior tothe project's planning stages. Although they may have interacted with other community organizations, they appeared not to have a history of predisposing problems or affinities among each other.

In sum, we have-described a network of service organizations, chosen as our case study, which fits the characteristics of a federation. We can now describe the methodology for analyzing whether the four hypotheses delineated in the previous chapter apply to this service federation. 
CHAPTER IV

METHODOLOGY

This chapter describes the methodology utilized in the examination of the federation of service agencies. After noting general characteristics of the case study method, we detail the data used in this study and the process of collecting them. Finally, some of the "operationalizations" used in ferreting through this information are listed, including the criteria for assessing hypotheses about interorganizational relations within federations.

The Case Study Method: Limitations and Possibilities

The case study method usually involves blending a number of information sources to acquire a more complete picture of a unitary phenomenon. The "breadth of data" usually obtained is valuable for probing different aspects of this unit (Goode and Hatt, 1952). For example, the case study is especially helpful in investigating process and developmental variables. In particular it is useful for forming typologies and clarifying the dimensions and measurement of concepts related to the phenomenon.

The case study in this instance offers certain advantages for interorganizational research. It readily captures the systemic or network flavor of relationships. Its reportage of these relationships can be more inclusive than an aggregate or summary statistics. In any case, few such measures are provided by the literature, and their development 
is not within the scope of this study.

Though the limitations of the case study for testing a theory are often bemoaned, guidelines can be followed to enhance its utility. Campbel1 (1975) recently posed this issue in considering the potential for rejecting an hypothesis. First, he observed that case studies do have this potential if they systematically describe the parameters of the case and the concepts being examined. An "antagonistic" approach toward hypotheses can be adopted by deliberately attempting to falsify them or find competing explanations.

Second, Campbell reasoned that the degrees of freedom available through a case study can be increased. Post hoc "tests" can be avoided. Multiple dimensions of the model can be tested. Confidence in data is increased if multiple sources of information are available, while conclusions are bolstered if multiple measures support the hypotheses. If Campbe11's suggestions are heeded, this approach can be valuable for studying a federation of social service relationships.

\section{Data Collection}

The data on this federation have been obtained from a variety of sources. Certain documents, including the minutes of meetings and monthly reports, are complete through the project's service delivery tenure. Other reports assist in sketching out incidents in the project's planning period. Also, monthly case monitoring records are available for the first year; these detail on an agency-by-agency basis the aggregate of referrals received and sent and the number of client activities accomplished. These sources are supplemented by the author's personal experience with the project's second operating year while an 
employee of its evaluation component.

A major source of information was obtained through a series of interviews. Over thirty interview sessions were conducted, over a two month period, with a representative from each of the nine contacted organizations being interviewed at least twice during this period. Other staff from most of the agencies were also interviewed. In addition, interviews were conducted with representatives from ten non-contracted agencies. These agencies had participated with project organizations in some service delivery capacity and were more or less familiar with its goals.

The interviews with representatives from the non-contracted agencies, however, required a different sampling approach. It was decided for reasons of economy that only agencies who had interacted with agencies in the project should be included. Therefore, a modified "snowball sample" was chosen. Workers from the federation agencies were asked which organizations they had come in contact with during the project's operation. A list which represented a continuum of these organizations "most interacted with" was derived from the frequencies of their responses, and from different points on this range ten organizations were chosen.

One methodological issue often facing the sampling of organizational personnel is whether a survey-sample approach or the use of "key informants" yields more valid and reliable data (Pennings, 1973). The problems were generally circumvented in this study by the small size and number of participating organizations. Almost all personnel contracted by the project (not including those participating as clerical 
or voluntary assistance) were sampled.

Moreover, this sample took into consideration the accounts of representatives of different levels of the organization (see Hage and Aiken, 1972, and Hall and C1ark, 1975, on this issue). In virtually all of the organizations interviews were held with those of the contracted personnel of managerial positions within the organization. Additional interview sessions were conducted with many "line" personnel.

All interviews covered a variety of project areas. The emphasis generally was an informant approach, but one which consistently included questions over the following subjects: the object and frequency of relations with other agencies, including which were contacted the most; problematic relations, such as lack of cooperation or poor. communication; how activities such as meetings facilitated more effective relations; that person's role in the project, and how it may have changed; and finally, other services and activities in which their organization was engaged.

The interview protocol, however, was intentionally not kept rigorous nor were the possible responses often closed. Many project activities and incidents were known prior to the sessions; therefore, a sensitivity to that person's impressions about these affairs, and to his organization's perspectives on them, was deemed to be more appropriate for an exploratory study than a standardized protocol. By following a more probing format, for example, several significant interorganizational incidents unknown to project administrators were discovered. With this format the length of the sessions varied, but most were between ninety minutes and two hours. 
Some remarks are in order regarding the validity of each of these data sources. The information on the official reports was viewed as useful especially for listing and locating events in time. Besides this chronology official reports often serve to corroborate or dispute information provided through personal accounts. However, they were assessed discriminately. Since official reports were usually compiled by project administrators both to inform and inspire, these accounts were tinged with an optimistic flavor. A certain skepticism should be maintained in perceiving as "data" information gathered however unobtrusively from "official" records of transactions.

Next, monitoring reports are also cautiously approached. Although appearing to provide the kind of "hard" data which sociologists so appreciate, their information occasionally is faulty. Particularly in the beginning phases of the project, and to some extent whenever system changes were initiated, the items of the reports were somewhat unstandardized. What was considered a "referral," for example, varied slightly among agencies.

Other aspects of the validity of the interviews can be discussed. First, they were held at the end of the project's tenure, which presumably allowed relational patterns to establish themselves over time. The thorn of relying upon people's memories of past events is assuaged in part through information in the project records. However, that respondent's perception or impression of past events as "real" is in any case an important type of data.

These interviews were generally conducted as part of an evaluation project. However, this potentially biasing factor is partially dis- 
counted on several grounds. Since the project in fact in most cases had less than a month to continue at the time of these interviews, the respondents may have had less at stake in an impending evaluation report. Also, they were told that the report would be written in such a way as to insure the anonymity of their responses. Finally, they were asked to be as candid as time would permit, and most appeared quite eager to be interviewed for the opportunity to "speak their mind" on the project.

\section{Data Analysis}

The "findings" of a case study are constructions from integrating and making conceptually coherent a diversity of data. Campbe11 (1975) warns that given its limitations for generalization, an emphasis on detail and specification of facts for a case study can be unwarranted. Nevertheless, the ideal of reliability is jeopardized by idiosyncratic interpretations or vaguely specified indicators of concepts. These potential pitfalls can be at least partially filled by matching some of the indicators of the hypotheses to be examined with operationalizations from the data. In so doing more systematic future replications and descriptive studies might be facilitated.

The hypothesis concerning the transactional subarea focused on reciprocity, which refers to the mutual flow of resources between agencies (Marrett, 1971:93). Resources can include clients, information, staff, and money. Thus, by examining monitoring records we can detect whether the flow of clients actually occurred according to the project's design. Interviews with agency personnel can reveal any "returns" of resources. Reciprocity can also refer to mutual participation in 
decision-making; here we can examine the extent to which agency actions altered or molded the balance of these resource flows.

Next, resource dependency refers to a lack of alternatives in input or output relationships and the desire of agencies to maximize alternatives. By examining the background information for each of the organizations we can hypothesize propensities to initiate alternative relationships, such as with non-contracted agencies. With referral data we can also examine discrepancies in organizational contact with other project agencies.

The hypothesis for the communication subarea emphasizes the relationship of characteristics of the "production process" with interorganizational communication within the federation. One technological facet is standardization, or the changeability of the elements or tasks to be coordinated (Litwak, 1970; ses also Perrow, 1972). By distinguishing between these tasks, we can correlate them with the opinions of workers for which type of communication is most preferable and effective.

Finally, the division of labor subarea involves the effects of interdependence, which can be measured by the extent of role specialization and the interagency referral design for the project as a whole. The relationship to the "stability" of relationships can be assessed through the extent of conflict and opinions of agency administrators.

Although each of these hypotheses has its own focus of content, overall the analysis probes the effects of the federation "as a whole" on relationships between organizations. This includes identifying the 
nature of the effects, noting which agents if any were directly responsible for them (such as the administrative component), and estimating how important these effects were. In other words, can the behavior of the agencies be understood without reference to the federation? For example, with the hypotheses about dependence, reciprocity, and "production processes" (when data are available) dyads of relationships can be examined to determine if patterns are as predicted. Since this is a case study of a relatively small cluster of organizations any statistical approximation of the strength of relationships between variables is at best crude. Because most of the hypotheses have a number of indicators, some arbitrary "weighing" of the evidence is inevitable. However, if effects of the federative context can be discerned, then conclusions can be made more firmly. Next, the forms of relationships between the variables of the hypotheses are important. If interorganizational relations were examined over a broad range of contexts, such as all four "fields" of interaction, the relationship could for example be linear, curvilinear, or involve "interaction effects" between fields. By analyzing only one field the "total variance" to be accounted for is limited. If a large sample of only federations were to be analyzed, the range for variables might be limited, and thus the surmised form of the relationships could be misleading. Therefore, we ultimately want to explore by extrapolating across interorganizational fields. Obvious limitations accrue with only one case available. Nevertheless, as mentioned, much of the research on these hypotheses has been on social choice fields, thereby making comparisons more feasible. 
In these ways general conclusions can be drawn about differences between interorganizational fields and the contribution which this level of analysis makes in explaining relationships between organizations. If federative influence can be distinguished in at least two of the four hypotheses, then tentative credence can be given to the importance of contexts. If these effects can be found for a majority of the hypotheses, this would be even stronger indication of support for considering this level of analysis. 


\section{CHAPTER V}

\section{AN EMPIRICAL EXAMINATION OF HYPOTHESES}

This chapter considers four hypotheses culled from the literature on interorganizational relationships by empirically examining phenomena from a federation of service agencies. This case study is guided by the methodological strictures specified in the preceding chapter. The hypotheses are segregated by their corresponding subareas to provide additional continuity and coherence to their evaluation. A brief review of operationalizations is presented for each hypothesis in order to facilitate more valid comparisons across interorganizational fields. Data analysis and interpretations of each are offered in turn. Based upon the analysis of these hypotheses, the remainder of the chapter offers a more inclusive assessment of this level of analysis. Consequences of participation in a federation are reviewed to discern the nature of any contextual effects. The implications for Warren's interorganizational field typology are pursued further in the concluding chapter.

The Transactional Subarea

HYPOTHESIS 1: The larger the amounts of resources at stake in a relationship between organizations, the more likely the transactions will be characterized by reciprocity.

This subarea is created by the juncture of the resource and linkage dimensions of interorganizations and the characteristics of the connections between them. Here the interorganizational linkages and 
their attributes are viewed as affecting, or being affected by, the organization's stake in the resources involved. Accordingly, the hypothesis for the transactional subarea involves the direction of resource flow within the federation.

Variations of this general assertion about reciprocity appear in much of the literature on interorganizational relations. Reciprocity indicates that there is in some form a mutual flow of resources between the parties involved (Marrett, 1972:93). Moreover, the benefits of these transactions are distributed on something akin to a parity basis, although the rewards can possibly be quite dissimilar and intangible (Litwak, 1970) .

However, assessments differ somewhat between analysts as to how important reciprocity is to a relationship. Levine, White, and Vlasak (1972) are most adamant that it is an essential ingredient to relationships, at times implying that relationships between non-profit agencies are similar to a "primitive barter situation," where "the needs of both the two participating parties must be fulfilled by a single exchange." A less extreme version of this proposal is that representatives from organizations are more likely to desire to interact with those agencies which can satisfy resource needs directly. A more minimal form of reciprocity is that a direct exchange is not necessary, but that some indirect exchange, such as through linkage with a third party, can satisfy the demands of those involved (see Litwak, 1970). The alternative to all of this, of course, is that reciprocity is not a necessary factor for interaction.

Measuring the degree of reciprocity is not necessarily straight- 
forward. Therefore, we will differentiate sectors of activity. Marrett (1971) has noted at least two aspects of transactions which can involve reciprocity: first, the extent to which the conditions of exchange are mutually agreed upon (voluntary), and second, the actual flow or transfer of elements between agencies.

Regarding making decisions on the conditions of exchange, we can distinguish between an agency's exercising influence in specific transactions with other agencies - at the operational level - and its negotiating with the federation as a whole regarding its role in the broader design of service delivery. The decision to participate in the federation was voluntary, of course. However, the agencies had to forget some voice regarding the basic roles which they were to play in the project. The origins of the project featured a "task force" of local agencies which in innumerable interagency conferences shaped the shell of the project's interagency scheme of services. Though these conferences in some, - not all - cases included input from the agencies which were to participate directly in services, basic plans were ratified by this task force, with some alterations by the project coordinator.

The final distinctive changes in the interagency design also were not predominantly in the hands of the agencies. Rather, the project coordinator was responsible for reducing the number of clients eligible for a certain "caseload" of clients. To be sure, the communication with and approval by different agencies was necessary, but again, the initiation of the pattern of service relationships was not really determined by mutual agreement between the agencies. Thus, 
there appeared to be some discrepancy in reciprocity of influence in formally outlining the basic modes of service provision and interorganizational transactions.

However, considering reciprocity of influence at the operational level of the project alters this picture somewhat. We described in Chapter Three how the exigencies of providing services forced some informal, often crescive changes in these plans. Although remnants of the original design remained, the service agencies exercised influence in important ways. First, although unplanned and usually in response to another agency's action, their initiatives altered the design by making the referral process more decentralized. Second, they frequently negotiated directly between themselves the informal procedures for referring and servicing clients, although the administration component often mediated these negotiations. For instance, the referral process was certainly not entirely unproblematic. However, particularly after the first six months of the project, this was as much a process of knowing an agency's capacity and criteria for service as it was a negotiation over authority.

Thus, the agencies over time did influence the development of the project by establishing the expectations and responsibilities of interaction. For example, at the inception of the project, there was for the service agencies ambiguity regarding how their actions were to fit together. As one person put it, it was necessary to be flexible, sometimes even to wait until another agency (such as a referral agency) had initiated a role for itself before establishing firm procedures of its own. Thus, sometimes relations between agencies featured certain 
idiosyncratic flavor. However, it appeared that all of the contracted agencies exercised influence in these negotiation processes, and not just particular agencies who referred or who received clients.

In sum, procedures for relations between agencies were often ad hoc and rarely formalized by mutual agreements. However, in this federation the necessity for establishing terms for daily operations of service provision resulted in informal agreements. These sometimes simply emerged over time, as decisions were made by one agency in response to decisions made in other agencies. Nonetheless, negotiation over the terms for interaction did occur, but it was often mediated or even encouraged by members of the administrative component.

Thus, by this indicator we can reject the extreme "primitive barter" version of the reciprocity hypothesis (Levine, White, and Vlasak, 1972). Instead, agencies did initiate and negotiate relationships, but these were primarily at the operational level and were often mediated in one way or another.

The second indicator of reciprocity regards the actual flow or transfer of elements between agencies. Reid (1964) lists many of these elements, including transfer of information, of clients (referrals), and of services.

First, the monitoring reports are useful here in indicating the extent to which the general design of the project was implemented. This design called for the referral component to provide most of the "intake" and referral services; clients would flow from these agencies to the contracted and other community agencies. Thus, this design did not call for a very direct reciprocity or exchange between agencies and 
accordingly provides an adequate test of the hypothesis. Its enactment can be verified by noting from the monitoring records the percentage of referrals received from the referral agencies as opposed to other agencies.

In turn, whatever the referral agencies received from these interagency efforts can be revealed through interviews with them. The interview data generally can reveal the extent to which reciprocity existed in dyadic relationships. Moreover, any reciprocity between project agencies can be contrasted with those benefits mentioned in interviews with non-contracted agencies. The indicators thus involve, first, whether an imbalance in exchanges occurred, and second, the enthusiasm with which the organizations and workers responded to the relationships.

Examination of the monitoring records indeed reveals that the referral design was enacted. Thus, for the first year at least, clients were referred when necessary (and when services were available) from the referral agencies to other contracted agencies. This pattern held for all three of the service agencies to other contracted agencies. This pattern held for all three of the service agencies (referral data from the nutrition sites were inadequate): seventy percent of clients serviced by protective services were from contracted referral agencies, as well as eighty percent of the homemaker clients, and almost one hundred percent of the legal aid clients were from this source. (Other reasons for this variation between these agencies will be discussed in the communication subarea.)

In contrast, the referral of clients usually did not flow in the 
opposite direction. Contracted agencies sometimes did refer clients back to a referral agency, but usually would curtail their responsibilities only after service delivery for that client had been terminated. Agencies generally preferred to take it upon themselves to refer clients to other agencies, though this assertiveness diminished somewhat over time.

Other resources can be involved in reciprocal transactions, however, including passage of information and providing services. Based upon interview data, we can note that information and other resources sometimes did flow between agencies. Only the protective services agency explicitly mentioned that information as a resource was shared with a referral agency, although some of the supervisors also considered their meetings valuable for this function. The other "exchange" noted between the agencies was more ongoing; it featured the referral agencies sponsoring meal sites for the nutrition agency. This arrangement appeared beneficial for both parties, since the referral agencies received added community and client esteem in return for some physical resources.

However, although there were these instances of reciprocity, resources did not simply flow back to the referral agencies as a transaction for clients. Rather, the agencies who most often noted that there was information exchanged were the referral agencies, but this exchange occurred among each other instead of with the other contracted service providers. Moreover, other than these referral agencies, no agencies mentioned exchange with more than one other contracted agency. In short, some reciprocity did occur, but it was sporadic and did not 
apply to many of the resources passed between agencies.

Finally, the interviews regarding non-contracted agency relationships indicate that transactions out of the federation were generally more reciprocal than those within the federation. of the six agencies interviewed, all mentioned having some form of an exchange relationship. The transactions generally were not based upon formal agreements, and in some cases the non-contracted agencies had mentioned exchanges with only one or two federated agencies. However, some larger organizations, such as the community health and welfare services, reported relationships with all of the federated agencies. The types of resources which flowed in these relationships appeared similar to relationships within the federation.

But an additional element which appears significant in examining these non-contractual relations is the perception or value attached to them. Interviews with the workers from the federation indicate that some form of exchange frequently facilitated a working relationship with other agencies in the community. As with relationships in the federation, it is difficult to assess "objectively" the balance of resource flow in these transactions. Nevertheless, the perceptions of the transactions by federation agencies seemed different; it was almost as though they were less routinized, and enthusiasm and value were attributed to the transactions because they could not be taken for granted.

This analysis of the transfer of resources within the federation does not indicate much reciprocity in interagency transactions. Based upon referral information, interview data, and the contrast of the non- 
contractual relations, both objective and subjective indicators imply a pattern of relations which acknowledged and affirmed the larger collectivity of agencies. The original service impetus of federation was sustained; apparently, the coordinative work succeeded in loosening some of the everyday strictures of interagency reciprocity.

In sum, both these two indicators-establishing the conditions of exchange and the actual flow of resources--call the reciprocity hypothesis into question. Though traces of bargaining and exchange can be found, a strict bartering form of reciprocity was certainly not the norm. Rather, the reciprocity which existed was more indirect, informal, and extended over time than the hypothesis predicted. Apparently the mediation of interagency relationships by the structure and development of the federation was a significant factor in diminishing the importance of reciprocity. Nevertheless, what reciprocity did exist probably increased the overall stability of the project.

Thus, if this hypothesis were examined across all four interorganizational fields, it is likely that there are interaction effects rather than a linear relationship between resources at stake and reciprocity. These interaction effects are probably due to greater certainty of transactions coupled with the mediation by third parties. Both of these are features of the larger context of interorganizational relations.

The Managerial Subarea

In this subarea the structural and resource dimensions of interorganizational relationships intersect. The structuring of relationships includes the administration by an organization of its input and 
output operations. These involve the procedures for establishing or avoiding the control or hierarchy between organizations. The concern of this administration lies with the resources which organizations can utilize. These resources, such as an organization's authority, domain, and its more tangible assets, constitute a bargaining element in this structuring of relations. The hypothesis which follows is germane to this concern with the utilization of resources in a federative context.

HYPOTHESIS 2: The more dependent Organization A is upon the the resources of Organization $B$, the more it seeks to develop (input or output) relationships with organizations C, D, and/or E.

A social service organization which has access to a limited supply of input or output relationships or resources typically recognizes that its environment is uncertain. In this kind of environment the organization's control over its position becomes much more tenuous, its operations potentially vulnerable to other organizations. Accordingly, such organizations would desire at the minimum to maintain some alternatives in its interactions, and at the maximum to exercise power and control over its environment.

This hypothesis has been proposed often by organizational theorists. (See Thompson, 1967; Aldrich, 1972b; Tropman, 1974). Some recent research has supported it; see, for example, Aldrich's (1976) study of employment service offices and social service agencies. However, it is necessary to supplement this line of thought by probing its application in different interorganizational fields; it remains for us to see if dependence is manifested similarly within a federation.

Resource "dependence" here is operationalized as a lack of alternatives in input or output relationships. The issue is whether the 
agencies contracted by the project attempted to minimize their dependencies by reserving alternative courses of action for themselves. The analysis basically involves noting the extent to which these agencies located and maintained working relationships other than with project agencies. This is accompanied by probing why the availability of these resource alternatives were or were not important to the agencies.

A brief survey of the agencies reveals a varied set of resource circumstances. The task here involves scanning where the agency would have been had it not participated within the project. Of those in the federation only one referral agency began operating with the inception of the project and was funded almost entirely by it, although it rapidly became assimilated into the community. The other referral agencies had each been active for a few years. Although they were fairly well endowed with volunteers and community domain, with the depletion of community action and local monies their statuses were clouded by some uncertainty. All but one had some sources of aid beyond involvement in the project, but most felt some pinch when the project trimmed funds the second year.

The service agencies generally featured somewhat less established but more "professional" programs. Two of them, the legal and the protective services, were formed with the project's inception but within the auspices of existing non-profit and state organizations, respective1y. Although their budgets emanated almost entirely from project funds, their employees were professional with marketable skills and therefore they had a measure of autonomy. The nutrition agency had also existed for a short span of time, but it was rapidly expanding its operations 
due to the sudden availability of federal funds. Finally, the agency which provided homemaker services featured the largest and probably the most "established," diversified domain within the community, although a significant portion of its budget too was composed of its allotment from the project.

However, though sources of support varied, overall dependence on the project for funding did not. Referral agencies relied more upon their integration into their localities and community funds whereas the other agencies featured more marketable, professional services, with less local competition for their services than was the case for the referral agencies. However, despite glimmers of independence, all depended extensively upon the project for organizational sustenance. For example, all of the agencies received a significant percentage of their budgets--in most cases from forty to sixty percent--from the project. Other than the general difference-between referral" and service agencies, and the prospects of future"federal funds for the nutrition component, it is difficult to discern appreciable differences of dependency of the agencies on the project.

The task now is to note if there were variations in the extent to which these agencies seized linkages which maximized their alternatives to interacting with project agencies. The referral data found in the monitoring reports are useful here. Given their resource contexts, the hypothesis would lead us to expect a generally high level of interest for all project agencies in diffusing their referral activity. The strongest indicator of minimizing dependence is extensive referral activity with non-contracted agencies. A weaker version would be 
diffusion of referral activity within the federation. This interest should involve a desire by agencies to accumulate resource alternatives while maintaining ties with the federation.

The resource alternatives important here to the referral agencies are their outputs, the agencies to which they send referrals. As Azumi (1972) posits, "when the organization has ... just one consumer on the output side, then the organization's dependency on the agent is maximized." We will consider 16 possible cases: each of the four referral agencies could desire to lessen dependency in their relationships with each of the four service agencies.

Instead, the patterns of referrals to project and non-contracted agencies confirm a more minimal or altered version of the resource dependence hypothesis. On the one hand, the total number of referrals (not including those to transportation services) to project services increased for one referral agency, remained fairly stable for two others, and decreased somewhat for the fourth agency. On the other hand, although it fluctuated more dramatically, the referral rate to non-contracted agencies increased over time distinctively for all but one of the agencies.

However, examination of records indicates that generally these non-contractual referrals are for services other than those provided by project agencies. That is, these were not alternatives but additional referrals. Although personnel from three of the referral agencies mentioned during interviews that they cultivated alternate agencies on which to depend, the reasons given for these outlets generally involved the need for more of a particular service. In one case, an agency 
TABLE I

NUMBER OF CLIENTS (AGGREGATED IN 4-MONTH SPANS)

REFERRED TO SERVICE AGENCIES

BY REFERRAL AGENCIES

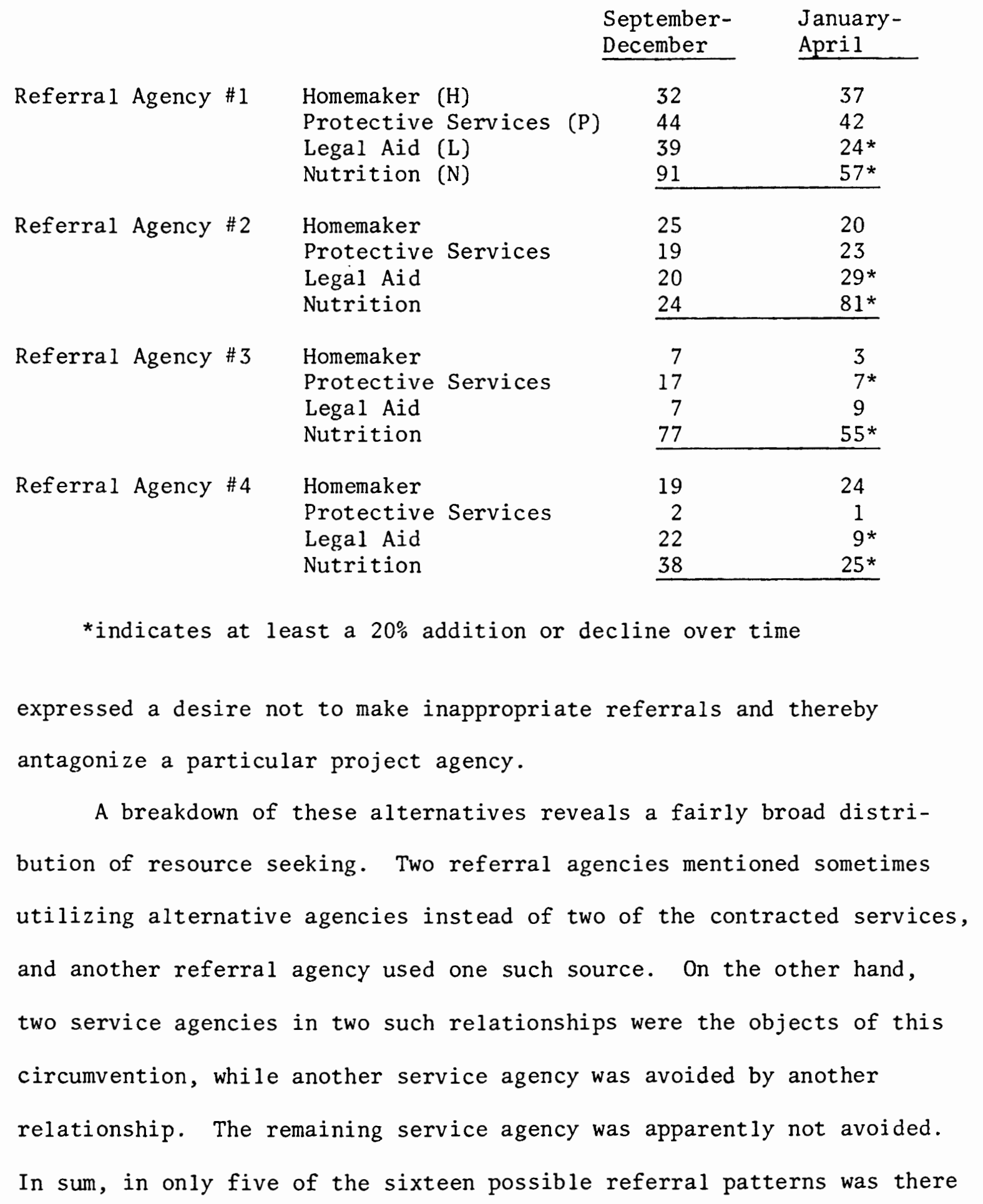


evidence of seeking alternative referral routes. Moreover, this circumvention did not occur in a uniform pattern--at least four different reasons for these routes were provided.

Other factors affected these referral patterns, however. First, the agencies were in fact encouraged by the administrative component to utilize existing community resources, to expand their domains within the community, and this mandate if anything preceded the rise in noncontracted referrals occurring after the first few months of the project. Although no strict boundaries were placed on relationships outside the federation, the stipulation was that this referral activity should not impede operations of agencies within the federation.

Moreover, this move toward domain expansion by the agencies seemed equally a result of the operational exigencies at hand. This push occurred in two ways. First, since the project was relatively new each referral agency experienced a rapidly growing clientele, yet experienced a shortage of federated resources and agencies to deal with client demands. Therefore, both alternative and service outlets were considered imperative if they were to maintain their legitimacy. Second, the agencies were hardly aggressive in pursuing alternative directions of referrals. As noted, the reasons frequently cited for these actions involved difficulties of linkage with particular project agencies, including a desire by workers to avoid recurrent misunderstandings or, in one case, simply the proximity problems of a service agency's 10cation on the outskirts of the city.

Resource alternatives for output are one means to lessen dependence; alternative sources of client input are another. Here the 
focus is on all the referrals directed to the service agencies. By examining whether referrals originated from within the project or from non-contracted agencies, we can discern tendencies to maintain ties outside of project agencies.

Different patterns for the four agencies can be quickly observed. For instance, the homemaker component was at the inception of the project probably the most "established" of the service agencies. At first, it accepted a large percentage of clients from non-contracted agencies, for it already had a large number of ties outside the contracted network of agencies. However, over time its contacts with contracted agencies increased while correspondingly the number of this kind of referral decreased dramatically (from $31 \%$ in the first six months to barely $10 \%$ in the second) by the end of the first year.

However, just the opposite occurred with the protective services agency. It was a new unit with few community ties. However, it was composed almost entirely of professional workers who, through the nature of their work, developed extensive ties with other non-contracted agencies. At the same time, as illustrated by fewer referrals, it interacted somewhat less with the contracted agency network than homemaker agency. These tendencies are revealed in the increasing number of referrals received from non-referral agencies: from twenty percent in the first six months to forty percent the second six months. In short, regarding the number of outside ties, this protective services agency reveals a trend just the opposite of the homemaker agency.

The legal aid component was different from both of these. Although smaller in operation, it was similar to protective services in 
that is was a new unit dominated by professionals. However, the data indicate that, for the first year of the project, ninety-nine percent of its referrals came from the project referral agencies, a pattern clearly discrepant from the proposal. Again, the type of service rendered appeared to set the interagency pace, for it was predominantly the counsel of one lawyer to her clients. In contrast to protective services, there was accordingly much less urgency in obtaining exchanges from other agencies.

The remaining service agency, the nutrition component, also featured a distinctive referral pattern. Most of those served were referred by project agencies. However, this agency found significant nourishment in outside funds and during the second year of the project received almost no project support. No other agency within the federation had such outside support. Yet the indication from interviews is that most of its clients still were referred by project agencies. Even with little fiscal support from the project, this agency relied upon and cooperated with it as much as any other agency.

This agency's action makes explicit a pattern more subtly exemplified by most other agencies, namely, that the federation as a whole, as a collective of organizations (Azumi, 1972), was considered a resource with which agencies must deal. Affiliation with it superseded the need to maintain linkage with any particular agency. In this case, the federation itself as a pattern of social organization supplied resource alternatives; thus dependence was mediated by the other interorganizational relationships available through it. That the federation shapes this availability becomes evident when we consider that even 
though almost half the project agencies received considerably less money during the second year, they too continued to cooperate with project coordination. Moreover, all but one administrator interviewed expressed considerable desire to maintain linkage with it. Since an interest in formalizing relationships can be one means of minimizing dependency by shoring up against uncertain environments (Aldrich, 1976), this desire again affirms the significance of the federation.

In sum, these data indicate that a modification of the resource dependency hypothesis must be considered. Alternative referral sources of inputs and outputs were sometimes important, but patterns here correlated as much with characteristics of the tasks to be coordinated as they did with linkages to resources. Instead, it appears the hypothesis must be revised to consider the nature of the interorganizational field. The agencies were interested in maintaining alternatives, but this occurred more within the relationships of the federation than with outside agencies. In other words, when resource, dependence was a concern, the federation was an intervening variable which directed or strongly affected any search for alternative relationships.

\section{The Communication Subarea}

Coupling the technological dimension with the linkage dimension results in a focus upon interorganizational communication, or the types of techniques involved in linking the efforts of functionally discrete agencies. Technology is a broad concept which encompasses the procedures and expertise involved in producing an output or delivering a service. For example, the preparation of meals by the nutrition agency entails a very different set of procedures and problems than the 
idiosyncracies of deciding to which agency a client should be referred. The hypothesis for this subarea is concerned with certain consequences of this "production process" or service delivery for interagency relations within the service federation.

HYPOTHESIS 3: Characteristics of the production process determine those forms of interorganizational communication which will be most effective.

This hypothesis is derived from the broader assertion that the forms of technology utilized for a talk will affect the ensuing structure of interorganizational relationships (Litwak, 1970; Lawrence and Lorsch, 1967). In this case the production process involves the knowledge about and the methods of providing the various project services, while the forms of communication refer to arrangements and procedures to coordinate interagency action. The implication is that the work process itself is an important independent variable that inevitably steers which course of coordination is taken.

The objective of analysis is to discern if the federative context alters or supersedes the effects of technology on communication between the agencies. Two indicators of the influence of technology are available. First, a survey of differences in the characteristics of the services provided by project agencies should allow us to find any correlations with differences in their communication patterns. Interviews can reveal what types of interorganizational communication workers feel are desirable as well as their assessment of their work process.

Second, patterns of referral rejections over an eight-month span of the first year of the project should also indicate the effects of the production process. If an agency's procedures for servicing a 
client vary to some extent with differences between clients, then we can expect an increase in interagency misunderstandings regarding when a clients is appropriately serviceable. Thus, there should be a higher rate of referral rejections for agencies whose criteria for accepting a client varies extensively. Further, the rejection percentage should for these agencies remain consistently high or increase as the project progresses. With these data we can discern any contextual effects, which could occur by increasing the importance of other variables affecting coordination or by influencing the nature of the technology itself.

Certain dimensions characterize the technologies of human service agencies. The "routineness" of the operation, which includes the complexity or possible variety of client needs and the amount of knowledge about how to treat them (Perrow, 1972), is a variable which can effect an organization's structure and its consequent disposition to interact with other organizations (Hage and Aiken, 1972). One relevant aspect of this routineness, for example, is how often the organization must interact with other organizations to mediate or negotiate for a client's situation as well as how problematic or unpredictable this process is for the agency. In a similar vein, Litwak (1970) argues that a crucial contingency for interorganizational relationships is whether the "events" or raw materials which an organization handles are standardized. We can organize a composite of these factors as our measure of "standardization," which expresses the nature of the intra-organizational technology that the agencies utilized in providing services. Litwak predicts that after controlling for certain conditions, such as a small 
number of organizations involved and a high awareness among them of the need for coordination, the degree of standardization should determine the level of intensity of interagency linkages most likely to be utilized. With low standardization he expects a high degree of intensity, with more informal interagency communication, an emphasis on joint staff meetings, and a certain "primary group intensity." In contrast, a high degree of standardization should result in lower intensity by permitting agencies to specify through general meetings the rules and instructions on the circumstances and procedures of communication. Between these extremes are instructional sessions or regularly scheduled meetings which confront alterations or new contingencies in interagency relations.

A survey of the work of the project organizations will allow us to test these predictions by differentiating which agencies would be most likely to want these types of interorganizational communication. We must note that human service organizations often are biased toward a human relations orientation which stresses primary group intensity as "an essential part of their milieu" (Litwak, 1970; see also White, 1972). Such rhetoric was used often, for example, by workers from the referral agencies.

However, the tasks of workers from referral agencies did feature unstandardized qualities. First, their tasks were not well specified at the start of the project, and their responsibilities were altered more than for workers from the other agencies during the course of the project. They also had to negotiate continuously in informal relationships with other community agencies. Finally, they were staffed by 
paraprofessionals who often did not have as much experience to exercise the judgment called for by casework and referral activities. Thus their work overall was unstandardized.

The activities of the protective services agency were also unstandardized. Although the workers were professionals, their cases usually called for diagnosing a variety of personal needs and for displaying judgment regarding appropriate actions. They too dealt with unpredictable interorganizational relationships.

The legal aid component also featured some unstandardized responsibilities. But although clients had a variety of needs, the actions required to meet them were somewhat more routine, given the requisite legal credentials for the task, than the practices of the protective services agency. A minority of cases did require substantial effort, and some entailed legal interaction with other parties.

In contrast, the tasks of both the nutrition and homemaker agencies were much more standardized. Neither was required to interact frequently with other agencies. For both agencies, but particularly the nutrition component, the variety of needs were much more circumscribed than for the other agencies. Thus, less expertise was necessary and appropriate actions were more easily diagnosed and delivered.

In sum, project agencies exhibited many levels of standardization in delivering their respective services. According to Litwak's hypothesis they should utilize corresponding intensities in communication techniques and preferences.

Information on what types of meetings were preferred by workers as most helpful was obtained through interviews. Three general cate- 
gories were listed, including the general forums, instructional sessions for learning how to respond to a general category of client problems, and the idiosyncratic "staffings" for workers dealing with problems regarding particular clients. These categories form an ordinal ranking of high, medium, and low interagency intensity. Thus, the predicted relationship is that high task standardization would be associated with low interagency intensity. However, deviations from expected relationships must be assessed by the pattern of preferences, since more than one category could be chosen. In other words, an agency with highly standardized activities might prefer a middle as well as low level of intensity, but should not choose middle and high intensity. With some exceptions, the indicators of task standardization and interagency communication techniques generally confirm these predictions. Only two agencies, including the nutrition component and one referral agency, chose the general meetings as very helpful. At the other end of the pole, three of the referral agencies - the protective services and the homemaker agencies - preferred the highly intensive staffings. A tally of these preferences reveals that only the homemaker and one referral agency deviated markedly from predictions.

Finally, half of the agencies indicated some preferences for the intermediate category of interagency intensity, which included instructional sessions and regular meetings between supervisors. Only two of the five agencies with unstandardized technologies preferred this category, while two of the three agencies with standardized technologies preferred it.

The general trend of referral rejections by three of the service 
agencies during the middle eight months of the first year also indicates the effects of the production process on interagency coordination, though with some qualifications. The prediction is first that the more unstandardized technology would lead to a higher rate of referral rejections, and second, that this technology would feature a constant or even increasing percentage of rejections through the project's tenure. As was predicted from its "nonroutine" technology, the percentage of rejections actually increased during this time from fifteen percent to twenty-two percent (see Table II). However, the overall percentage of rejections was a moderate eighteen percent.

\section{TABLE II}

REFERRAL REJECTIONS FOR THREE PROJECT AGENCIES

DURING EIGHT MONTHS OF THE FIRST YEAR

$\begin{array}{lll}\text { Protective } & \text { Homemaker } & \text { Legal } \\ \text { Services } & \text { Agency } & \text { Aid }\end{array}$

Referra1s Rejected:

August-November

14

96

2

December-March

16

56

0

Tota 1

30

152

2

Referred and Served

August-November

93

100

56

December-March

71

82

87

Total

164

182

143

Percentage Rejected

$\begin{array}{llll}\text { August-November } & 15 \% & 96 \% & 2 \% \\ \text { December-March } & 22 \% & 68 \% & 0 \% \\ \text { Total } & 18 \% & 83 \% & 1 \%\end{array}$

In contrast, the referral rejections by the homemaker agency are not so easily interpreted. Since it features a more standardized tech- 
nology than protective services, this agency should feature a lower and declining percentage of rejections. However, though the percentage does decline this agency has a total rate of rejections of eighty-seven percent, certainly much higher a percentage than protective services. Some interpretation of these rejections comes from project records which indicate that the homemaker agency not only had a higher volume of clients but apparently less operating capacity. By all accounts the agency early in the project was overwhelmed with referrals. Thus, the rejection percentage declined from almost one hundred to sixty-eight percent.

The third agency is the legal services agency, which also featured a more standardized technology. Thus, its very low rate (overa1l, one percent) of referral rejections conforms to predicted patterns. Moreover, to expedite coordination the legal agency held for the referral workers a series of sessions devoted to identifying the most frequent legal problems of clients which should be referred.

In sum, the patterns of rejections also indicate the importance of the production process, though somewhat less conclusively than the patterns of interagency communication.

As previously discussed, one other response regarding difficulties of coordination is that they were "developmental." This response refers to viewing misunderstandings as "inevitable," especially at the start of such an intense, interorganizational effort, as well as when adjustments must be made when the project or its agencies altered basic procedures or service orientations. Virtually every agency, including the administration component, maintained such coordination problems 
are "bound to happen" over time but are nevertheless exceptions in the overall interorganizational harmony.

The picture which corresponds with these comments about the project's development is encased in references to participation in it for two years. Most workers mentioned that the increased breadth of experience gained in interagency phenomena facilitated confronting the coordination issues which frequently emerged. For example, the lawyer for the legal services attested to this experiential factor by noting the increase in "appropriate" referrals by referral workers. The project coordinator similarly stated that this enhanced interorganizational judgment and homemaker components, which by the end of the second project year rarely contended the appropriateness of referrals. The development of the project is indeed epitomized by the nutrition component, which by this time rarely needed to meet with other agencies to accomplish its responsibilities.

Taken as a whole all these data confirm the importance of an agency's technology in determining its interorganizational relations. However, the federation as a context of interaction supplemented and shaped these effects in significant ways. First, the prospect of continued participation in the federation meant that agencies generally had to resolve problems of coordinating services. Though the agencies reserved the flexibility to avoid some issues, they were aware that a level of detail in arrangements and understandings had to be reached if the project was to continue. This awareness was enhanced by the administration component, which encouraged and mediated these ongoing settlements. 
Second, the sheer frequency of interaction quickened the pace of inter-agency familiarization. The high intensity of referrals and other communications actually expedited becoming knowledgeable about which referrals were appropriate or which cases called for workers from other agencies.

Thus, it appears that regarding technology, the project functioned as an intervening variable. The federation functioned to close and intensify the development of the interorganizational system. Thus, it provided the setting to shape, indeed possibly enhance, these effects of technology. For example, the greater frequency in handling particular problems was itself staged by the interorganizational context (Perrow, 1972). The complexity of factors affecting interorganizational phenomena does not mask either the general importance of technology or the specific effects of the federation.

\section{The Division of Labor Subarea}

This subarea focuses upon the interaction of the technological and structural dimensions of interorganizational relationships, reflecting the literature's interest in how the tasks and goals of different organizations merge to affect the production process (see Thompson, 1967). Many relationships are oriented towards producing some specific output; the division of labor in this service federation featured a rather elaborate strategy for organizing and sequencing its coordination of service delivery. In this section the existence and the effects of these efforts are examined through the interdependence and conflict which they engendered. 
HYPOTHESIS 4: The greater the (facilitative) interdependency of relationships, the greater the stability of the transactions.

Interdependency generally refers to an overlap of interests, to an agency's taking the actions of other agencies into account when planning its own operations (Hage, 1975). The circumstances of interdependence can vary extensively from two organizations being directly dependent upon each other to their being mutually dependent upon a third party, to a combination of these two contexts (Mott, 1968). These structural variations of interdependence between organizations can affect the potential for stability and conflict (Mott, 1968; Reid, 1964). One type of arrangement, one which is featured in the interorganizational design of this service federation, is facilitative interdependence, where all parties can benefit to some extent from coordinating their efforts. Depending upon the structure of relationships, then, the consequences of interdependence can be beneficial or threatening to the input or output performances of organizations (Litwak, 1970). Thus, we would expect for this federation that a stable network of relationships would accompany a very interdependent structuring of relationships .

Interdependence includes various characteristics which affect the operation of the project as a whole. Relationships are more interdependent when there is common usage of some service or facility, when sequences of work or information flow are prescribed by task or hierarchy, and when some consensus exists about joint activity (Pondy, 1967:318; also Thompson, 1974). An important factor is the extent of functional specialization, including knowledge and execution of roles 
and tasks within the project (Litwak, 1970). Indicators of these characteristics revolve around the degree of centralization and specialization achieved in the project. Centralization is illustrated in the project's referral designs as these were altered over time, while specialization can be assessed through referral data.

Interviews with workers and administrators provided evidence of consensus of agency stances toward joint activity. These workers saw themselves as participating in an interagency project which was more inclusive than merely an agreement to refer clients to other organizations. While their perspectives emanated from their organization's interests and responsibilities, the workers nonetheless spoke of the project as a coordinated endeavor. This necessarily entailed a certain compliance with the administrative component if project and agency goals were to be accomplished. In short, agency personnel conceived of the project as a system which provided a design for service delivery which could not be offered by a single agency. The general consensus on these issues formed a background for interdependent activity.

The administration utilized these views to develop a design for referral which required a high degree of centralization. The original project referral design entailed the four referral agencies intaking prospective recipients and then shuttling these along to a central referral post housed with the administrative component. This central referral post was to evaluate which referrals were actually qualified clients and then to refer these to the appropriate agencies--whenever these agencies had the capacity to provide the services. In short, this was a highly interdependent design; the behavior of any agency would 
have ramifications for the other agencies.

This coordination scheme collapsed very quickly. Obviously the scheme gave the project's administrators more control over client characteristics. However, this structure robbed agency officials of the autonomy of deciding whom they would refer and whom they would serve. Most important, the central referral post was quickly inundated with prospective clients. As a result, clients were not getting served, and the referral agencies began bearing the external pressures of client wrath. Conflict and misunderstanding ensued over when and where clients should be referred.

The second referral scheme was an ad hoc arrangement informally implemented by the end of the first six weeks of the project. It was a much more decentralized scheme, though most referrals were still supposed to flow from the referral agencies to appropriate services. Data from the monitoring forms for this period indicate that this interagency division of labor did generally occur: almost $90 \%$ of all intakes came from the referral agencies.

However, this scheme still featured facets of the original referral design. Though less centralized, the scheme did not encourage much direct reciprocation between agencies. For example, relatively little information exchange occurred beyond immediate servicing of a client.

An important example of the type of interdependence fostered through this design involved relationships with the transportation component. This consisted of a van and a driver stationed at a referral agency. The result of this positioning was that the referral agencies 
had some discretion over who got rides, and when. This arrangement slowed the service process to some extent. As a consequence, the service agencies were dependent on the referral agencies to some extent both for referrals and for access to transportation services. Given this imbalance of access, and the lack of immediate, reciprocal ties for settling squabbles (except for common ties to the administrative component), interagency conflict tended to escalate easily.

The third referral scheme, which was operationalized a little over a year after the project's inception, was even more decentralized. Transportation was made more accessible to the other service agencies. Moreover, these service agencies were permitted to handle more intake activities, thereby becoming less dependent on the referral agencies for clients. At the same time, the referral agencies had become more proficient at utilizing whatever community resources existed, thereby lessening the necessity for making demands upon the project agencies.

This third scheme emphasized that some agency should shoulder responsibility for the client's welfare. Accordingly, the agencies gained some autonomy in accepting and referring clients. Thus, there was less specialization of function, more exchange of information, fewer differences in interorganizational status, and somewhat more reliance on non-contracted agencies.

Although this sequence of referral designs illustrates a decreasing degree of interdependence, other bases for interdependence developed as experience with the project increased. Coordination required some familiarity with the circumstance of clients and procedures of other organizations. Learning and making "roles" within this system 
evidently required a period of adjustment, especially given the limited experience of agencies with interorganizational endeavors. Thus, understandings and expectations did develop regarding how agencies would respond to events; interviews indicate, for example, that referral workers became more skilled at identifying referrals which other agencies would consider appropriate.

In sum, by these measures this service federation maintained a moderately intense degree of interdependence. Overall interdependence did not increase; if anything it declined during the course of the project. The hypothesis for this subsector would therefore be that the stability of relationships decreases as the level of interdependence declines.

The "stability" of these arrangements, though somewhat more difficult to measure, can be examined through consequences to project agencies. These include first, the degree of satisfaction of workers and administrators with relationships. Second, the converse of stability can be noted by probing conflicts of interests between agencies. Data on these indicators come from interviews with agency officials and project records.

However, though the level of interdependence declined, the stability of the federation appeared to grow over time. Interorganizational relations were by all accounts most problematic during the first year of the project. Interviews indicated that participants were least satisfied with interagency arrangements during this period. Indeed, in an interview the head of the administration component somewhat loosely described "coordination" during this period as breaking up 
interagency conflicts! Project records verify the frequency of these antagonisms .

Some of the tensions abated as the referral design was altered. The more decentralized schemes facilitated more feedback between agencies regarding clients. With better information, more appropriate referrals and services could be provided. And with more autonomy for decision-making, satisfaction and initiative gradually increased.

But the significant level of interdependence continued to have some adverse effects on project stability. In an interview the project coordinator summarized these effects as system ambiguities and as system capacity. System ambiguities referred to misunderstanding, lack of information and unclear division of labor between agencies. The increased flow of information resulting from alterations in the referral design helped to articulate agency roles with the federation. Of course, these effects were in part a result of lack of interorganizational experience. As previously discussed, understandings did develop over time as agencies clarified their roles.

Problems with system capacity are easily traced to interdependence. For example, the deluge of referrals during the first year indicated to the administration component that ignoring an agency's capacity to serve clients could disrupt the larger system of activity. A majority of workers interviewed agreed that an overall lack of resources within the federation resulted in conflict over how to handle the demands that this. volume of referrals created. In short, the level of interdependence resulted in serious reverberations throughout the federation. One important factor in these reverberations was the increasing 
number of relationships initiated with non-contracted agencies in the community. First, these functioned to lessen the interdependence within the federation by providing an outlet for serving the volume of clients. Second, having relationships with non-contracted agencies increased the alternatives which project agencies had. Instead of having to work with each other (due to the small number of organizations in the federation) they could choose which agency was the most appropriate for a client. Moreover, agencies could more easily avoid relationships which were troublesome, and several agencies remarked that they had avoided conflicts in this way.

The availability of these alternatives has been termed "system redundancy" (Landau, 1969). The possibility of different routes for clients functioned as "safety valves," reducing pressure on system parts when obstacles to providing services loomed. For example, at first the referral agencies did not have many relationships with other service agencies. Thus, for example, when the homemaker agency reached its capacity, the dearth of alternatives proved to be a source of conflict.

The relationships between interdependence and interorganizational stability now become more clear. A certain level of interdependence apparently did support more stable relationships. The design of the project facilitated defining organizational responsibilities and client characteristics. Further, there were many indications that the division of labor and affiliation with a publicized project strengthened desires of personnel to stay with the project.

But the interdependence which can be planned in a federation 
allows more intensity, more centralization, than within the social choice field. Thus, the federation permits examining what in this case appeared to be the upper limits of a usually positive relationship between interdependence and stability. That is, for this federation the relationship was curvilinear; up to a point, interdependence facilitated a harmonious system, but beyond that it became inefficient.

In short, interdependence within a system can be too "tight." The importance of flexible alternatives and flow of information cannot be ignored. The development of relationships over time, the nature of the technology utilized and the small number of organizations were all important system contingencies. Nevertheless, they do not mask the aspects of the system ambivalence which interdependence contributed.

The Impact of the Federation on Interorganizational Relationships

Taken together these findings emphasize that relationships between organizations are significantly affected by context. Interaction effects were found for three out of four of the hypotheses; the predicted relationships did not adequately depict what occurred. Since there is evidence that all these hypotheses do hold for other interorganizational fields, their lack of support here clearly justifies specifying and incorporating characteristics of this federative context into a theoretical framework.

The variety of contributing factors. and their effects can be noted. Here the conditional nature of many relationships can be emphasized. Thus, the range of variables comprising the context can be seen as interacting to form a distinct overall contingency for relationships between organizations. To name other factors, the frequency of 
interactions, the number and size of organizations, and the alternatives available were all network parameters which were interconnected to affect organizational behavior. When building a theory of federations elaborate sets of hypotheses could be constructed to take the interaction of these parameters into account (for examples, see Litwak, 1970; Litwak and Hylton, 1962).

However, it must be emphasized that features of the federation itself were found to alter or enhance the relationships for each of the hypotheses. It was not simply that hypotheses were not confirmed. Rather we can assert that it was agents or factors which emanated from the federation which led to the different results. Two factors in particular can be recognized.

First, the analyses just completed indicate that many of these factors were associated with the network structure of relationships. This structure featured certain distinct consequences for interorganizational behavior. The referral design, for example, which was created and altered by the administration component juxtaposed by agency demands, functioned most conspicuously to shape the flow of resources within the federation.

Other network characteristics contributed more indirectly to how the project developed. Because the project created boundaries for relationships, the interactions were more intense and frequent, which in turn enhanced the significance of the production process. Similarly, the umbrella of time in which these relationships could develop or endure may in itself have contributed to the stability of the federation. In short, the network of relationships in the federation could be 
altered to achieve a shape not as likely found in other interorganizational fields.

The underlying dynamic entwining the interorganizational network was that the federation was seen as a collectivity in itself. That is, the federation--its hierarchy, division of labor, collectivity orientation of the agencies, etc.--was considered by the agencies comprising it to be a force in establishing these causal parameters. It was often regarded as underlying the regulation of alternatives available, the number of participating organizations, and the distribution of referral patterns.

The second, and most important, factor is that the federation as a collectivity became an overriding contingency for agencies to consider in making decisions about resources. Agency representatives did not stress the resources gained or expended in any particular project relationships. In fact, the organizations did not generally calculate the rewards and the costs of participation in any single relationships with other contracted agency. Instead, dyadic relationships were enmeshed within the network of organizations.

Most of the rewards mentioned were associated with the broader operations of the federation. Almost all of the agencies felt that affiliation with the project had benefited their internal operations. For example, several stated that their record-keeping and accounting procedures had been refined, and that the staff and operations of their agencies had been enlarged. Next, virtually all the agencies stated that their domain within the community had been enhanced. Affiliation with a publicized project was seen as instrumental in pro- 
moting ties with the community, including a clientele of aged and a coterie of other service providers. Finally, all agencies mentioned that participation in the federation had facilitated a grasp of how to link with other agencies, including simply their availability as well as the prohibitions and procedures for establishing linkage.

It is equally important, however, to note that the pattern for assessing costs of participation with the project was similar to that for rewards: the federation as a whole was seen as responsible for certain agency ills and interagency antagonisms. For example, two of the referral agencies felt that the project's publicity had to some extent usurped the community credit which these agency's efforts deserved.

Regarding the federation's system of operation, all but one agency found the project's emphasis on serving only a certified clientele to be something of a hindrance in stimulating non-contracted service exchantes. The general shortage of staffing which plagued most agencies in the project, coupled with the everyday exigencies of providing services and coordinating efforts, were usually summed up by workers as the "frustrations" of participation in a federation. Such irritations as "slowness" or delays in feedback were generalized as systemic problems and not usually mentioned as issues specifically regarding another agency.

The data indicate that the federation was regarded as a network from which rewards, costs, and resource alternatives emanated. In addition to mediating relationships, affiliation with this larger collectivity superseded the importance of deciding whether to link with 
any particular agency. Relations with multiple organizations had to be considered when evaluating a particular transaction with another agency. The initial issue was whether to partipate in the project as a whole. After that, the issue was how to participate.

The idea that organizational decision-making depends upon the characteristics of the network in which that organization is enmeshed involves a twist to the "norms of rationality" presumed to govern interorganizational relationships (Thompson, 1967). It is not that organizations eschew rationality or neglect their own interests. Rather, in this case any "rational calculation" was encumbered by considering the complexity of the resources which relationships with the federation offered. Agency strategies of participation within the federative context clearly required a complicated scale of "satisfying" or weighing of many factors which accrued with participation. Thus, what defines self-interest can become nebulous.

One example involves autonomy of decision-making. Though the agencies appeared to lose some autonomy, this was compensated in part by the added certainty and mediation of relationships which participation in the federation helped provide. Moreover, as Azumi (1972) has pointed out, while autonomy of an agency within the federation is perhaps lessened, the autonomy of the network of organizations can be increased. That is, the added bargaining power and visibility through participation in the network can facilitate transactions with agencies outside the federation.

Many of these factors developed over the course of the project. For example, there surfaced a normative or value component which 
stressed the importance bcth of unity of effort and of the needs of the clientele. Indeed, this was fostered in part by the administrative component and in part by the agencies themselves. For the latter (especially the referral agencies) these values did correspond nicely with a rhetoric of "advocacy" for the elderly, in part serving to legitimate their activities.

This conceptualization contrasts with those which characterize organizational decision-making as existing within dyadic contexts. Many propositions, such as with reciprocity (Levine and White, 1961) and resource dependence (Aldrich, 1976) tend to assume conditions similar to social choice fields. Their emphasis was that given conditions of uncertainty, organizations would "rationally" consider the alternatives available (Thompson, 1967). All this sometimes ignores how organizations can be involved in ongoing networks of relationships. It is significant that much of this literature has tried to predict the initiation rather than the maintenance or re-directing of relationships. The final chapter considers the implications of these findings for developing a model of interorganizational fields. 


\section{CHAPTER VI}

\section{CONCLUSION - TOWARD A MODEL OF INTERORGANIZATIONAL FIELDS}

Interorganizational relationships can adopt many different configurations.. This paper has documented one type of configuration, a federation of social service agencies, as it operated over a two year period. Other patterns of relationships and the conditions under which they emerge have been presented in the literature (see Litwak, 1970; Hage, 1975; Reid, 1964). In his typology of interorganizational fields, Warren (1967) acknowledged this diversity when he differentiated four types of configuration. These fields varied according to certain characteristics, including hierarchy, division of labor, and collectivity orientation.

Yet the consequences of participation in these different contexts have been given inadequate attention. Warren's typology illustrates two of these deficiencies. Though it identifies many important elements, it lacks an objective. Whereas the typology succeeds in establishing an interorganizational level of analysis, it does not really specify any dependent variables or phenomena which result from the differences in interorganizational fields. Warren only suggests that "new forms of interaction" can emerge with different contexts; he does not elaborate upon what these might be.

Second, the interorganizational field typology neglects the nature of the organizational response to different contexts. It ignores 
how organizations make decisions to interact depending upon the kinds of contingencies or constraints presented to them. This results from its static conceptualization: there is no discussion at this level of analysis of the processes or development of interaction between organizations.

In response to these deficiencies this paper has explored the types of consequences which differentiate interorganizational contexts. Though focusing upon a single case, its research has suggested that across fields there can be significant differences in the relationships between variables. Further, these differences run counter to several prominent hypotheses on relationships between organizations. What remains is to elaborate Warren's typology by outlining the skeleton of the model of interorganizational contexts. The findings just described can be directly employed here. There are two basic objectives. One is to predict which relationships between variables-presuming a relationship exists in one context--interact with interorganizational field conditions. That is, what kinds of variables are most affected by changing circumstances.

Second, the model must explain why certain relationships are affected by context but not others. This entails explicating the nature of the dynamics or the causal process emanating from interorganizational field conditions. For example, part of the explanation must necessarily consider the nature of the organizational response to the interorganizational conditions surrounding them.

Five elements comprise this model of interorganizational fields. Included are the environment, the characteristics of interorganizational 
fields, the reward-cost calculation for organizations, the network structure of relationships between organizations, and the types of variables which are affected. This model also displays the relationships between these elements. Each is considered in turn.

The focus of "dependent variable" of the model is the range of relationships between variables. Depending upon how the variables are categorized, a broad spectrum of variables could be encompassed. The typological scheme created in the second chapter illustrates such a range. Thus, the question becomes which of its four subsectors (transactiona1, managerial, communication, or division of labor) will predictably yield interaction effects which will maintain a stable relationship across fields. However, changes in the classification schemes, such as using one by Van de Ven, Emmett, and Koenig (1975) could produce different results.

An important element in the model is the environment. This also can be broken down by many categories or dimensions (see Hal1, 1972; Aldrich, 1972a). In any case it includes the number and size of possibly competing organizations, the extent and sources of resources which are available, as well as the ethos, rhetorics or cultures surrounding relationships between organizations (Warren, Rose, Bergunder, 1974). Highly relevant are the authority structure and legal conditions which can govern interaction, for obviously they can mandate, regulate, or otherwise impinge upon relationships. The environment also typically creates the prevailing technology both for organizations and for relationships between them such as with computers or telephones. This may account for the smaller effects of the federation upon the production 
process than for the remaining subareas. All these factors can directly affect other elements in the model.

The environment also exerts indirect effects by affecting the creation and operation of interorganizational fields themselves. In the case study just presented an agency outside the federation (the state agency for the aging) disbursed funds provided by the federal government, as mandated by Congress. The community itself proved to be receptive and even supportive to this federation, in contrast to some programs organized through the War on Poverty (see Warren, Rose and Bergunder, 1974).

However, this model does grant causal significance to the fields, just as Warren (1967) advocated. The characteristics differentiating interorganizational fields have also been discussed (see Chapter I). The significant feature of the model is its specification of two effects of interorganizational fields, the calculus for rewards and costs and the network structure exhibited in the interactions of the organizations.

The calculation of rewards and costs by the organizations involved in a federation or other field becomes an element in this model. This calculation process involves the various resources which organizations typically desire for self-maintenance. These resources can and often do emanate from the environment. However, characteristics of the interorganizational field organize and distribute the resources. The participating organizations must acknowledge these patterns depending upon, for example, if they wish to compete or cooperate with organizations in that field (see Thompson and McEwen, 1972). 
Resources are always important to organizations, but the definition of a resource can vary. In this case study the organizations considered a number of factors which were quite interwoven with participation in the federation, including a normative element, the reciprocity which was less direct and which prevailed over time, and the lessened dependence upon any organization in particular. The sheer complexity of decision-making under these circumstances leads to an altered calculation of what is beneficial to the organizations.

The second identifiable element stemming from the characteristics of fields is the network structure of relationships. This structure had numerous consequences for this federation. It featured a boundaried set of relationships, which resulted in increasing the frequency and interdependence of interaction. The division of labor within the federation affected the flow of resources and the asymmetry between organizations, another network trait. By restructuring the intensity and direction of interactions, the federation enlarged the parameters of relationships between variables. These relationships thereby could assume curvilinear form, as with the relationship between interdependence and stability of relationships. In short, the federation could create network conditions not approximated in other fields.

Specifying these last two elements clarifies some of the contextual effects which previously were nebulous. They involved intervening processes created by the composition of the interorganization field. As with the other elements of this model, they correspond to cluster of variables which are important to theory construction (Blalock, 1969). This skelet on of a model thus remains an outline. 
The purpose is to summarize the results of this case study by re-casting the interorganizational field typology into a more purposeful and specific mold.

Because this is a case study, this model necessarily leaves at least two tasks for future research. First, the importance or overall contribution of each element remains to be tested. A comparative design exploring multiple cases is essential here, with attention particularly given to variance in the environmental and interorganizational field elements. Obviously, a complete test would not just examine similarly funded federations, but would include a range of environmental circumstances and interorganizational fields. In addition, this test would require greater specification of variables for each element.

On a more limited focus, comparative research could establish how much impact the interorganizational fields does have. There is considerable debate about the potential of federative arrangements for yielding more "effective" services (Hall, 1972). Levine, White, and Vlasak (1972) argue that federal funding for federations of health agencies "does little in itself to integrate the functions of the various organizations and indeed leads to fission in the system." In contrast, Hage (1975) maintains that structures similar to federations are viable for incorporating the delivery of services within the community context to produce at once a more accountable and more effective coalition of interested parties. In either case more consideration of these contexts seems necessary as environments become more consolidated or turbulent (Aldrich and Pfeffer, 1976; Emery and Trist, 
1965).

The second task involves noting additional elements which the model could include. For instance, a significant element left unincorporated involves the development or change of a field over time. In this case study developmental variables appeared frequently, albeit in multiple guises. Agency administrators and project leaders themselves often mentioned that there are stages to such interorganizational endeavors. Their implication was that which factors are crucial can change as the project gets altered, that different factors can be more salient to the project as it develops. For example, pooling and obtaining sufficient resources for the project are especially crucial in initial stages, whereas the style of project leadership and the "commitment" exhibited by agencies can assume more importance as operations get underway.

The literature on the development or emergence of relationships over time is sparse but suggestive. Hall and Clark (1975) sketch the proposition that "interorganizational relationships have an impact on themselves. Interactions once begun contribute to the quantity and quality of subsequent interactions." In an insightful discussion of social intervention agencies, Spergel (1969:128) outlines five phases of organizational development, including initial interorganizational structures and the struggle to modify them over time. He speculates that understanding this developmental process should assist anticipating and perhaps mitigating many problems or conflicts of interest which are likely to emerge during a project.

Indeed, a model of stages may be one way to incorporate conflict 
variables. Overcoming some interorganizational hurdles creates the conditions for other conflict situations. In this conceptualization conflict and agency self-interest can be explicitly considered as endemic to a federation rather than being optimistically written off. The findings about interdependence in the preceding chapter serve to illustrate that integrated action is fraught with dilemmas.

These considerations uphold the usefulness of considering interorganizational fields. Mustering resources and relevant agencies is only the inception of a larger flow of interaction. An understanding of the interorganizational structures which can be established and of the appeasement of the self-interests of participating agencies becomes crucial. The importance of these factors was illustrated in this study of a social service federation, where they affected the viability and maintenance of interorganizational relationships. 


\section{REFERENCES}

Aiken, Michael and Robert Alford. "Community Structure and Innovation: The Case of Urban Renewal." American Sociological Review, 35 (August, 1970), pp. 650-66.

Aiken, Michael and Jerald Hage. "Organizational Interdependence and Intraorganizational Structure." American Sociological Review, 33 (1968), pp. 912-929.

Aldrich, Howard. "An Organization-Environment Perspective on Cooperation and Conflict Between Organizations in the Manpower Training System. Quarterly Journal of Management Development, 3 (1972a), pp. 11-37.

Aldrich, Howard. "Organizational Boundaries and Interorganizational Conflict." Human Relations, 24 (August, 1972b), pp. 279-293.

Aldrich, Howard. "Resource Dependence and Interorganizational Relations: Local Employment Service Offices and Social Services Sector Organizations." Administration and Society, 7 (1976), pp. $419-454$.

Aldrich, Howard. "Organization Sets, Action Sets, and Networks: Making the Most of Simplicity." In Paul Nystrom and W. Starbuck (eds.), Handbook of Organizational Design. Amsterdam: Elsevier Scientific. 1977.

Aldrich, Howard and Jeff Pfeffer. "Environments of Organizations." In Alex Inkeles (ed.), Annual Review of Sociology, Volume II. Palo Alto, California, 1976.

Azumi, Koya. "Environmental Needs, Resources, and Agents." In Koya Azumi and Jerald Hage (eds.), Organizational Systems.

Lexington, Massachusetts: D.C.Heath. 1972. Pp. 91-101.

Baker, Frank and H,C. Shulberg. "Community Health Caregiving Systems: Integration of Interorganizational Networks." Chapter 8 in A. Sheldon, F. Baker, and C. McLaughlin (eds.), Systems and Medical Care. Cambridge, Massachusetts: M.I.T. Press, 1970.

Benson, J. Kenneth. "The Interorganizational Network as a Political Economy." Administrative Science Quarterly, 20 (1975), pp. 229-249. 
Blalock, Hubert. Theory Construction: From Verbal To Mathematical Formulations. Englewood Cliffs, New Jersey: Prentice-Hall. 1969 .

Blau, Peter. Exchange and Power in Social Life. New York: John Wiley. $1 \overline{964}$.

Braito, Rita, Steve Paulson and Gerald Klonglon. "Domain Consensus: A Key Variable in Interorganizational Analysis." In Merlin Brinkerhoff and Phillip Kunz (eds.), Complex Organizations and Their Environments. Dubuque, Iowa: Wm. C. Brown. 1972.

Campbe11, Donald. "Degrees of Freedom and the Case Study." Comparative Political Studies, 8 (1975), Number 2.

Cherry, Ralph L. "Toward an Interorganizational Model of the Area Agency on Aging." Paper presented at annual meetings of Gerontological Society, Louisville, KY. 1975.

Clark, Burton. "Interorganizational Patterns in Education." In Brinkerhoff and Kunz (eds.), Complex Organizations and Their Environments. Dubuque, Iowa: Wm. C. Brown. 1972.

Davidson, Stephen. "Planning and Coordination of Social Services in Multiorganizational Contexts." Social Service Review, 50 (1976), pp. 117-137.

Demone, Harold and Dwight Harshbarger. A Handbook of Human Service Organizations. New York: Behavioral Publications. 1974.

Dill, William R. "Environment as an Influence on Managerial Autonomy." Administrative Science Quarterly, 2 (1958), pp. 409-443.

Di11, William R. "The Impact of Environment on Organizational Development." In Sydney Marlich and Edward Van Ness (eds.), Concepts and Issues in Administrative Behavior. Englewood Cliffs, New Jersey: Prentice-Ha11. 1962.

Emery, F.E. and E.L.Trist. "The Causal Texture of Organizational Environments." Human Relations, 18 (1965), pp.21-31.

Evan, William M. "The Organization Set: Toward a Theory of Interoorganizationa1 Relations." In Brinkerhoff and Kunz (eds.), Complex Organizations and Their Environments. Dubuque, Iowa: Wm. C. Brown. 1972 .

Frey, James. "Interorganizational Relations and Effectiveness: A Balance Model." Paper presented at annual meetings of Pacific Sociological Association, Pheonix, Arizona. 1973..

Gilbert, Neil and Harry Specht. Dimensions of Social Welfare Policy. Englewood Cliffs, New Jersey: Prentice-Ha1l. 1974. 
Gouldner, Alvin. "Organizational Analysis." Pp. 400-528 in Robert Merton et.al. (eds.), Sociology Today. New York: Basic Books. 1959.

Guetzkow, Harold. "Relations Among Organizations." In Raymond V. Bowers (ed.), Studies on Behavior in Organizations. Athens: University of Georgia Press. 1966.

Goode, William and Paul Hatt. Methodology of Social Research. New York: McGraw Hill. 1952.

Hage, Jerald. "A Strategy for Creating Interdependent Delivery Systems to Meet Complex Needs." Pp. 210-235 in Anant Negandhi (ed.), Interorganizational Theory. Kent, Ohio: Kent State University Press. 1975.

Hage, Jerald and Michael Aiken. "Routine Technology, Social Structure, and Organizational Goals." Pp. 55-72 in Richard Hall (ed.), The Formal Organization. New York: Basic Books. 1972.

Ha11, Richard. Organizations: Structure and Process. Englewood Cliffs, New Jersey: Prentice-Ha11. 1972.

Ha11, Richard and John Clark. "Problems in the Study of Interorganizational Relationships." Pp. 111-127 in Nehandhi (ed.) Interorganizational Theory. Kent, Ohio: Kent State University Press. 1975.

Hall, Richard, et. al. "Interorganizational Relationships." Paper read at annual meetings of the American Sociological Association, New York. 1974.

Halpert, Burton. "Interorganizational Relationships: An Interactionist Approach." Paper presented at annual meetings of the American Sociological Association, San Francisco. 1975.

Hasenfe1d, Yeheskel. "People Processing Organizations: An Exchange Approach." American Sociological Review, 37 (1972), pp. 256-263.

Hegland, T.J. and Nylen Borre. "Adjustment of Work Organizations to Critical Environmental Factors." Acta Sociologica, 11 (1968), pp. 31-54.

Johns, Ray and David Demarche. Community Organizations and Agency Responsibility. New York: Association Press.. 1951.

Klonglan, Gerald, Steven Paulson, and David Rogers. "Measurement of Interorganizational Relations: A Deterministic Model." Paper read at annual meetings of American Sociological Association meetings, New Orleans. 1972. 
Landau, Martin. "Redundancy, Rationality, and the Problem of Duplication and Overlap." Public Administration Review, 29 (1969), pp. 346-358.

Lauffer, Armand, "Area Planning for the Aging." Unpublished Manuscript, School of Social Work, University of Michigan, Ann Arbor. 1974.

Lawrence, Paul and Jay Lorsch. Organization and Environment. Boston: Harvard Graduate School of Business Administration. 1967.

Lefton, Mark. "Client Characteristics and Interorganizational Functioning: An Interorganizational Focus." In Anant Negandhi (ed.), Interorganizational Theory. Kent, Ohio: Kent State University Press. 1975.

Levine, Sol and Paul White. "Exchange as a Conceptual Framework for the Study of Interorganizational Relationships." Administrative Science Quarterly, 5 (1961), pp. 583-601.

Levine, Sol, Paul White and Benjamin Paul. "Community Interorganizational Problems in Providing Medical Care and Social Services." American Journal of Public Health, 53 (1963), pp. 1183-1195.

Levine, Sol, Paul White and George Vlasak. "Exchange as a Conceptual Framework for Understanding Interorganizational Relationships: Application to Nonprofit Organizations." In Negandhi (ed.), Modern Organizational Theory. Kent, Ohio: Kent State University Press. 1972 .

Lindbloom, Charles. The Intelligence of Democracy. New York: Free Press. 1965.

Litwak, Eugene. "Towards the Theory and Practice of Coordination Between Formal Organizations." Pp. 137-187 in Lefton and Rosengren, Organizations and Clients. Columbus, Ohio: Charles Merrill. 1970 .

Litwak, Eugene and Lydia Hylton. "Interorganizational Analysis: A Hypothesis on Co-ordinating Agencies." Administrative Science Quarterly, 6 (1962), pp. 395-415.

Litwak, Eugene, and Henry Mayer. "A Balance Theory of Coordination Between Bureaucratic Organizations and Community Primary Groups." Administrative Science Quarterly, 10 (1968), pp. 31-58.

Marrett, Cora B. "On the Specification of Interorganizational Dimensions." Sociology and Social Research, 56 (1971), pp. 83-99.

Marris, Peter and Martin Rein. Dilemmas of Social Reform. New York: 
Melchar, Arlyn and Raymond Adamek. "Interorganizational Exchange." In Negandhi (ed.), Interorganizational Theory. Kent, Ohio: Kent State University Press. 1975.

Mott, B.J.F. Anatomy of a Coordinating Council. Pittsburgh: University of Pittsburgh Press. 1968.

Mitche11, J. Clyde (ed.). Social Networks in Urban Situations. London: Manchester University Press. 1969.

Morrissey, Joseph, Patrick Horan, and Patricia Rieker. "Interorganizational Relations." Paper presented at annual meetings of the American Sociological Association, San Francisco. 1975.

Pennings, Johannes. "The Measurement of Organizational Structure." American Journal of Sociology, 78 (1973), pp. 686-704.

Perrow, Charles. "Goals in Complex Organizations." American Sociological Review, 26 (1961), pp. 854-865.

Perrow, Charles. "A Framework for the Comparative Analysis of Organizations." Pp. 48-68 in Brinkerhoff and Kunz (eds.), Complex Organizations and Their Environments. 1975.

Pfeffer, Jeffrey and Anthony Leong. "Resource Allocations in United Funds." Social Forces, 55 (1977), pp. 775-790.

Pondy, Louis. "Organizational Conflict: Concepts and Models." Administrative Science Quarterly, 14 (1967), pp. 499-506.

Reid, William. "Interagency Coordination in Delinquency Prevention and Control." Social Service Review, 38 (1964), pp. 418-428.

Reid, William. "Interorganizational Coordination in Social Welfare." In R. Kramer and H. Specht (eds.), Readings in Community Organization Practice. Englewood Cliffs, New Jersey: Prentice-Hall. 1969.

Rose, Stephen. The Betrayal of the Poor. New York: Schenkman. 1973. Rosengren, William. "Organizational Age, Structure, and Orientations Toward Clients." Social Forces, 47 (1968), pp. 1-11.

Rosengren, William and Mark Lefton (eds.). Organizations and Clients. Columbus, Ohio: Charles Merrill. 1970.

Rothman, Jack. "Three Models of Community Organization Practice." Pp. 22-38 in Fred Cox-et. al. (eds.), Strategies of Community Organization. Itasca, Illinois: F.E. Peacock. 1974.

Selznick, Philip. TVA and the Grass Roots. Berkeley: University of California Press. 1949. 
Simpson, Richard and William Gulley. "Goals, Environmental Pressures, and Organizational Characteristics." American Sociological Review, (1962), pp. 344-351.

Spergel, Irving A. Community Problem Solving. Chicago: University of Chicago Press. 1969.

$\checkmark$ Sundquist, James. Making Federalism Work: A study of Program Coordination at the Community Level. Washington, D.C.: Brookings Institute. 1969.

Terreberry, Shirley. "The Evolution of Organizational Environments." Administrative Science Quarterly, 12 (1968), pp. 590-613.

Thompson, James. D. Organizations in Action. New York: McGraw Hill. 1967.

Thompson, James. D. "Social Interdependence, the Polity, and Public Administration." Administration and Society, 6 (1974), pp. 3-21.

Thompson, James D. and William McEwen. "Organizational Goals and Environments." American Sociological Review, 23 (1958), pp. 23-31.

Tropman, John E. "Conceptual Approaches in Interorganizational Analysis." Pp. 144-158 in Fred Cox et.al. (eds.), Strategies of Community Organization. Itasca, Illinois: F.E.Peacock. 1974.

Van de Ven, Andrew, Dennis Emmett, and Richard Koenig. "Frameworks for Interorganizational Analysis." Pp. 19-38 in Negandhi (ed.), Interorganizational Theory. Kent, Ohio: Kent State University Press. 1975.

Warren, Roland, Stephen Rose and Ann Bergunder. The Structure of Urban Reform. Lexington, Massachusetts: D. C. Heath. 1974.

Warren, Roland. "The Interorganizational Field as a Focus for Investigation." Administrative Science Quarterly, 12 (1967), pp. 396-419.

W Warren, Roland. Truth, Love and Social Change. Chicago: Rand McNally. 1971 .

Warren, Roland. "The Interaction of Community Decision Organizations: Some Conceptual Considerations and Empirical Findings." In Anant Negandhi (ed.), Modern Organizational. Theory. Kent, Ohio: Kent State University-Press. 1972.

Warren, Roland. "Comprehensive Planning and Coordination: Some Functional Aspects." Social Problems (August, 1973), pp. 355-364. 
White, Paul. "Myth and Reality in Interorganizational Behavior: A Study of Competition Between Two National Voluntary Health Agencies." American Journal of Public Health, 58 (1968), pp. 289-304.

White, Paul. "Fusion and Fission: A Consideration of the Cohesion and Interrelationships of Organizations." Paper presented at annual meetings of American Sociological Association. 1972.

Zald, Mayer. "The Structure of Society and Social Service Integration." Social Science Quarterly, 50 (1969), pp, 557-567.

Zald, Mayer. "Organizations as Polities: An Analysis of Community Organization Agencies." Pp. 95-104 in Fred Cox et. al. (eds.), Strategies of Community Organization. Itasca, Illinois: F.E.Peacock. 1974 . 